NBSIR 79-1773

Protective Coatings for Steel Structures:

Part 1 - Survey of Air Force Coating Problems and Development of an Interim Guide Specification

\author{
P. G. Campbell \\ G. A. Sleater
}

Structures and Materials Division

Center for Building Technology

National Engineering Laboratory

National Bureau of Standards

Washington, D.C. 20234

Interim Report (Official Distribution Only)

June 1979

Prepared for

Department of Air Force

Headquarters Air Force Engineering and Services Center

Tyndall Air Force Base, Florida 32403 

PROTECTIVE COATINGS FOR STEEL STRUCTURES:

PART 1 - SURVEY OF AIR FORCE COATING PROBLEMS AND DEVELOPMENT OF AN INTERIM GUIDE SPECIFICATION

P. G. Campbell

G. A. Sleater

Structures and Materials Division

Center for Building Technology

National Engineering Laboratory

National Bureau of Standards

Washington, D.C. 20234

Interim Report (Official Distribution Only)

June 1979

Prepared for

Department of Air Force

Headquarters Air Force Engineering and Services Center

Tyndall Air Force Base, Florida 32403

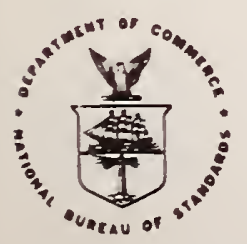

U.S. DEPARTMENT OF COMMERCE, Juanita M. Kreps, Secretary Jordan J. Baruch, Assistant Secretary for Science and Technology

NATIONAL BUREAU OF STANDARDS. Ernest Ambler, Director 



\section{ABSTRACT}

A survey of coating/corrosion problems encountered in steel structures maintained by the Air Force was made. Eighty-eight bases responded to the questionnaire sent and the responses were analyzed for 1) the type of structure involved, 2) surface preparation, 3) coating systems used, 4) time before the problem appeared and 5) the painting cycles commonly used by the Air Force Bases. An inspection tour was made to Patrick, MacDill, Tyndall and Eglin Air Force Bases to observe coating/corrosion problems. An interim guide specification was developed for corrosion preventive coating systems on steel.

Key Words: Coating systems; painting cycles; steel structures; surface preparation; survey of coating/cottosion problems. 


\section{List of Illustrations}

1. Map of the United States showing Air Force Base Location and Degree of Coating/Corrosion Problems

2. Map of the Contiguous United States Showing Climatic Conditioning According to Trewartha and the Reporting Air Force Base Locations

3. Coating/Corrosion Problems Versus Type of Steel Structure

4. Coating/Corrosion Problems Versus Type of Surface Preparation Used

5. Coating/Corrosion Problems Versus Type of Coating System Used

6. Coating/Corrosion Problems Versus Time Before Problem Appeared

7. Frequency of Air Force Base Painting

8. Water Tower, Patrick AFB, Overall View of Tower Undergoing Repair

9. Water Tower, Patrick AFB, Loose Support

10. Water Tower, Patrick AFB, Corroded Bolts

11. Water Tower, Patrick AFB, Corroded Support Rods

12. Water Tower, Patrick AFB, Recently Painted Water Tower

13. Water Tower, Patrlck AFB, Base of Recently Painted Water Tower

14. Water Tower, Tyndall AFB

15. Water Tower, MacDill AFB, Zinc Rich Inorganic, Vinyl Topcoat

16. Water Tower, Eglin AFB, Interior View of Vinyl Coated Riser

17. Heating Stack, Dover AFB

18. Hanger, Dover AFB, Coating Failure on Galvanized Steel Cladding

19. Nose Dock, Patrick AFB

20. Nose Dock, Mac Dill AFB, Delamination of Elastomeric Coating

21. Nose Dock, Mac Dill AFB, Delamination of Elastomeric Coating

22. Hangar, Dover AFB, Detail at Cladding-Concrete Block Interface

23. Hangar Doors, Tyndal AFB

24. Hangar Doors, Tyndal AFB, Detail of Unpainted Area 
25. Steel Support Beams, Patrick AFB

26. Steel Support Beams, Dover AFB

27. Steel Support Beams, Patrick AFB, Exhibit

28. Steel Support Beams, Mac Dill AFB

29. Fuel Tank Farm, Patrick AFB

30. Fuel Tank Farm, Patrick AFB, Detail of Failure in Saddle Area

31. Fuel Tank Farm, Patrick AFB, Detail of Repainted Tank

32. Fuel Tank, Seymour Johnson AFB

33. Communication Tower, Tyndall AFB

34. Communication Tower, Tyndall AFB, Detail

35. Communication Tower, Tyndall AFB, Detail

36. Communication Tower, Tyndall AFB, Detail 
ABSTRACT $\ldots \ldots \ldots \ldots \ldots \ldots \ldots \ldots \ldots \ldots \ldots \ldots \ldots \ldots \ldots \ldots \ldots \ldots \ldots \ldots \ldots \ldots \ldots \ldots$

LIST OF ILLUSTRATIONS ............................ iv

1. INTRODUCTION $\ldots \ldots \ldots \ldots \ldots \ldots \ldots \ldots \ldots \ldots \ldots \ldots \ldots \ldots \ldots \ldots \ldots \ldots \ldots \ldots \ldots$

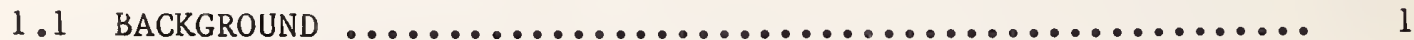

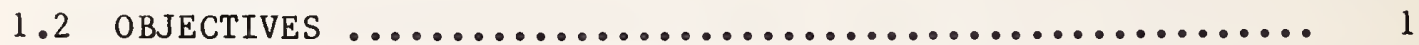

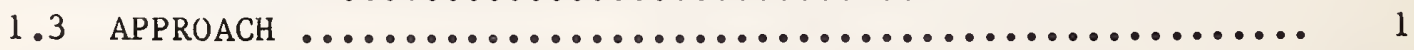

2. RESULTS AND DISCUSSION $\ldots \ldots \ldots \ldots \ldots \ldots \ldots \ldots \ldots \ldots \ldots \ldots \ldots \ldots \ldots \ldots$

2.1 QUESTIONNAIRE $\ldots \ldots \ldots \ldots \ldots \ldots \ldots \ldots \ldots \ldots \ldots \ldots \ldots \ldots \ldots \ldots \ldots . \ldots \ldots \ldots$

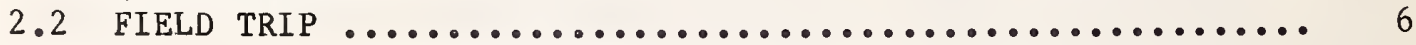

3. INTERIM COATINGS GUIDE SPECIFICATION .................. 10

4. SUMMARY $\ldots \ldots \ldots \ldots \ldots \ldots \ldots \ldots \ldots \ldots \ldots \ldots \ldots \ldots \ldots \ldots \ldots \ldots \ldots \ldots \ldots \ldots$

5. ACKNOWLEDGEMENTS $\ldots \ldots \ldots \ldots \ldots \ldots \ldots \ldots \ldots \ldots \ldots \ldots \ldots \ldots \ldots \ldots \ldots$

6. REFERENCES .................................... 12

APPENDIX A SAMPLE QUESTIONNAIRE ....................... 13 APPENDIX B INTERIM SPECIFICATION FOR PAINTING OF HIGH VALUE STEEL STRUCTURES ........................... 18

\section{LIST OF TABLES}

Page

Table 1. Color Code Schedule ..........................

Table 1. Tabulated Questionnaire Responses from 88 Air Force Bases 


\section{INTRODUCTION}

\subsection{BACKGROUND}

The Federal Government owns many structures, facilities and equipment that are subject to corrosion. Maintenance, repair and replacement expenses of these items resulting from corrosion represent a significant percentage of the total U.S. cost of corrosion which has been estimated by Bennett, et al. [1]* to be 70 billion annually. As part of the same study, Battelle Columbus Laboratories [2] estimated that corrosion maintenance costs for real property in the Air Force is $\$ 60$ million per year. However, Stevens [3] has estimated that total Air Force corrosion costs more nearly approached $\$ 300$ million per year, based upon detailed currosion cost studies at a number of Air Force Bases. An appreciable proportion of the losses were related to atmospheric corrosion; and coatings on steel structures maintained by the Air Force required replacement of 3-5 year intervals. Bennett et al. [1] estimated that 15 percent of the annual corrosion costs could be available for other uses through the use of presently available technology. Modern industrial coatings materials and application procedures can provide finishes with 10-20 years of life. Thus, it is desirable to review the current coating practice used at Air Force facilities as an initial step towards the development of guide specifications, inspection procedures, and coatings procedures used by the Air Force.

\subsection{OBJECTIVES}

The objectives of the study described in this report were to survey and evaluate current Air Force coatings practices for the protection of steel and to develop an interim coatings guide specification based upon the findings of the surveys and upon existing knowledge. The interim guide specification will be modified as needed pending the results of ongoing laboratory and field research.

\section{$1.3 \quad$ APPROACH}

To survey current Air Force coatings practices on steel, a questionnaire was developed and sent to all 127 Air Force Bases. The questionnaire requested information on the areas of predominant complaints, specific problems, painting schedules, surface preparation, types of materials used, etc. Based upon the responses, a field survey was made of Bases which had reported severe coatings/corrosion problems. The results obtained from the questionnaire responses and the field survey, combined with existing coatings knowledge, were used to develop an interim guide specification for coating steel structures.

Figures in brackets refer to references in Section 5 of this report. 


\section{RESULTS AND DISCUSSION}

\subsection{Questionnaire}

A questionnaire concerning the protection of steel was developed and sent to all Air Force Bases. The questionnaire (Appendix A) consisted of two parts: the first part included a request for information of a general nature, e.g., dominant complaints, periodicity of painting, paints used; and the second part included information on specific paint problems, e.g., structure, type of steel, surface preparation, coating system used, etr.

The questionnaire was developed by the authors and it was sent by the Air Force to every active Base. Eighty-eight Air Force bases replied to the questionnaire. The response to the questionnaire, are tabulated in Table 1. The predominant complaints of the respondents ranked in numeri.cal order were 1) poor surface preparation; 2) poor quality paints; 3) adhesion to galvanized steel; 4) excessive paint build up; 5) lack of manpower and materials funding for painting and surface preparation; 6) intercoat adhesion failures/paint incompatibility; 7) expense of white or near white metal blast, painting in winter or in poor weather, lack of contractors with qualified personnel to paint high steel structures, inadequate training for paint inspectors, no paint testing; 8) poor application by contractors, resulting in a relatively short period of protection.

Based upon the questionnaire responses, each base's corrosion/coating problems were arbitrarily assigned into three categories: 1) no coatings/ corrosion problems reported or performance reported as being normal, 2) some coatings/corrosion problems, and 3) extensive coatings/corrosion problems. The responding Air Force Base locations and degree of coatings/corrosion problems are depicted in Figure 1.

In general, coatings/corrosion problems were reported throughout all of the contiguous United States although most of the extensive problem areas were concentrated along the sea coast of the southeastern states.

In a study of corrosion costs of Air Force and Army facilities, Hahin [4] established the validity of predicting corrosion costs from climatic, topographir, geographic and environmental sources. Superimposing the dir Force sites onto Trewarths's [5] climatological map of the United States illustrates the relationship between climate and coating/corrosion problems (see figure 2). With regard to climate and base locations 31 bases were lor:ated in a $\mathrm{Ca}_{\mathrm{f}}$ climate (humid subtropical, no dry season), 14 bases were lorated in a Daf climate (humid continental, warm summer, no dry season), 14 bases were located in a Db $\mathrm{f}_{\mathrm{f}}$ limate (humid continental, cool summer, no dry season), 7 bases were located in a $\mathrm{C}_{\text {s }}$ climate mediterranean), 7 bases located in a BsK (middle latitude desert), 6 bases were located in a BWh climate (tropical and subtropiral desert), 3 bases were loc:ated in an $\mathrm{H}$ clinate (highland), 2 bases were located in a $\mathrm{Cb}$ climate (Marine West Coast), 2 bases were located in an $A_{f}$ (tropical 
rainforest), 1 base was located in an AW climate (tropical savanna) and 1 base was located in an ET climate (polar tundra). Since the Air Force bases are widely distributed throughout the United States, the reported results could serve as the basis for a "corrosion map" of the United States. However, to prepare a definitive "corrosion map", either a highly trained coating/corrosion team evaluating each of the bases or a report from each of the bases, based upon a precise set of guidelines and photographs to identify and tabulate coating/corrosion problems and reviewed by a team of experts would be required.

The questionnaire responses indicated that coatings/corrosion problems were different for the various climatic regions. For example, based on the responding bases in the $\mathrm{Db}_{\mathrm{f}}$ region (humid continental, cool summer, no dry season) four bases reported no problems and eleven bases reported some problems, while of the responding bases in the $\mathrm{Ca}_{\mathrm{f}}$ region (humid subtropical, no dry season), six bases reported no problems, fourteen bases reported some problems, but seven bases reported that there were appreciable corrosion/coatings problems present. However, the Paints and Protective Coatings manual, AFM 85-3, offers a choice of over 50 different coating systems for steel related to environment, type of substrate and degree of surface preparation. In spite of the large number of coating system choices available, for the different climatic conditions, Air Force bases, as well as other service facilities have had continuing problems with coatings on steel. The alternative of specifying only a limited number of coating systems for steel that would be suitable for all climatic regions, appears to be more reasonable than using the present system of selecting one of a number of coating systems for each particular environment.

The questionnaire results relating coating/corrosion problems to the type of steel structure involved are listed in Figure 3. It may be noted that the responses from each base will differ depending on the number of reported problem structures or even whether the base has any problem with their steel structures. The structures most commonly reported as having coating/corrosion problems were of galvanized steel and structural steel. The buildings affected were generally hangars, nose docks, warehouses, etc. where the exterior siding of the facility was galvanized steel, asphalt coated galvanized steel, or steel which was supported by structural steel. Also, hangar doors, railings, steel swimming pool walls, missile launch facilities, galvanized steel walkways, etr. were covered in these categories. As expected, most of the problems occurred in climatic regions where there was appreciable moisture present e.g. $\mathrm{Ca}_{f}, \mathrm{Da}_{f}, \mathrm{Db}_{f}, \mathrm{Aw}$. Of interest, there were almost as many problems reported in bases in the Daf (humid continental. warm summer, no dry season) and $\mathrm{Db}_{f}$ (humid continental, cool summer, no dry season) climates as bases in the $\mathrm{Ca}_{f}$ (humid subtropical, no dry season) climate although there were 31 responding bases in the $\mathrm{Ca}_{\mathrm{f}}$ :limate region and 14 bases each in the $\mathrm{Da}_{f}$ and $\mathrm{Db}_{\mathrm{f}}$ regions. Next in frequency of coating/corrosion problens reported were water towers and water treatment facilities. Most of the problems were on the exterior surfaces and this could be directly related to the predominant use of an oil, alkyd primer topcoat systen. 
Several bases reported failures with the interior coating system and this could well be attributed to the widespread use of vinyl coating systems, e.g. VR-3, which require abrasive blast cleaning as a surface preparation requirement. Fuel tank coating/corrosion problems were next in order of frequency. The problems noted were mostly on the exterior although personnel at one base remarked that the interior of one of their fuel tanks was continually pitting at the base.

Most of the exterior surfaces of fuel tanks which had problems had also been painted with an oil, alkyd primer topcoat system. Most of the problems associated with coating failures on smoke stacks occurred where the heat resistant coating, TT-P-28, had been used and the bases were in the $\mathrm{Db}_{\mathrm{f}}$ (humid continental, cool summer, no dry season) climate region. The antennas, communication towers and similar structures where problems had been reported were mostly in the $\mathrm{Ca}_{f}$ (humid subtropical, no dry season) climate region and three of the problems involved use of maintenance oil, alkyd primer topcoat system while two of the problems involved factory applied coatings new construction. One obvious reason why structures of this type would have coating/corrosion maintenance problems is the difficulty in above ground paint application and inspection. There were an appreciable number of bases that responded where 'no or only normal' coating/corrosion problems existed. The possibility arises as to whether many of the bases are not fully aware of all the corrosion problems present. An appreciable, number of bases within the Cs (mediterranean), Bsk (middle latitude desert), Cb (marine west coast) and ET (polar tundra) climate regions had no prublems.

The coating/corrosion problems reported were also related to the type of surface preparation used. The types of surface preparation used by most bases corresponded to the following Steel Stuctures Painting Council (SSPC) specifications [6]: SSPC-SP-2 Hand Tool Cleaning; SSPC-SP-3 Power Tool Cleaning; SSPC-SP-5 White Metal Blast Cleaning; SSPC-SP-6 Commercial Blast Cleaning; SSPC-SP-7 Brush-off Blast Cleaning; SSPC-SP-10 Near-white Blast Cleaning. The number of problems versus the type of surface preparation are illustrated in Figure 4. Most of the coating/corrosion problems occurred on surfaces where hand/mechanical cleaning was used. Many surfaces prepared by commercial blast cleaning also failed. Undoubtedly, the number of problems reported for Air Force structures cleaned by hand/ merhanical methods, i.e., SSPC-SP-2, 3, indicated that the preponderance of steel strurtures were prepared for painting this way; but it may be possible that structures prepared for painting by near white/white metal blast cleaning may not have had as many coating/corrosion problems. Of interest, most of the problems occurring where hand/mechanical cleaning was used, also were in humid climate areas, e.g., Caf $\mathrm{Da}_{\mathrm{f}}, \mathrm{Db_{f }}$. $_{\mathrm{f}}$

The questionnaire results relating coating/corrosion problems to the type of cuating system used are illustrated in Figure 5. The number of paint systems used where problems occurred were rather limited and the problems versus coating system seemed almost independent of climatic conditions. By far, the most widely used system consisted of an oil, alkyd primer, e.g., TT-P-86, TT-P-645, TT-P-57, and an oil, alkyd topcoat, e.g., 
TT-P-102, TT-P-105, TT-E-489. Also, eight bases located in marine environments reported coating failures with an oil, alkyd paint system. The problems with the use of a vinyl coating were connected with the use of this coating in water treatment or water storage areas. One base reported a problem with a zinc rich organic primer and an alkyd topcoat. A similar phenomenon was observed with a coatings problem that occurred at McGuire AFB a few years ago in the fuel storage tank area where there was intercoat adhesion failure between the zinc rich organic primer, TT-P-1046, and the silicone alkyd topcoat, TT-E-490. It was determined that oxidation products of the zinc on the primer surface prevented good adhesion and also, the probability that the silicone alkyd topcoat was saponified. Current coating practices do not recommend the use of alkyd or silicone alkyd coatings over zinc rich primers. While one base reported problems with the use of an alkyd primer, silicone alkyd toproat system due to poor application, a number of bases are replacing alkyd topcoats with silicone alkyd topcoats. The unique system of a zinc rich inorganic primer, urethane topcoat offers a combination of extremely durable components. However, Barksdale AFB reported a problem with this system and this may have been related in part to the excess coating thickness of 14 mils. Problems relating to the failure of an arrylic latex paint, TT-P-19, were related to painting over galvanized steel or an asphalt coated galvanized steel substrate. Three bases reported coating failures with aluminum paint, TT-P-28, used on high temperature smoke stacks. Interestingly, all of these bases are located in a $\mathrm{Db}_{\mathrm{f}}$ climate (humid continental, cool summer no dry season) and the question may be posed whether climatic conditions or high localized concentrations of pollutants inay have retarded the curing of the paint before exposure to high temperatures. The reported problems where the coating system used was unknown were due to the fact that the coatings had been factury applied.

The responses to the question of how soon did the coating/corrosion prublems occur were very interesting. While some failures were reported as orcurring within a day as one extreme, the early failures were all categorized into 6 months or less as shown in Figure 6 and they represented the majority. Most of the failures orcurring within 6 months were from structures where the Air Force base was located on a humid climate area, e.g. $\mathrm{Ca}_{f}, \mathrm{Da}_{f}, \mathrm{Db}_{f}$. At the other extreme where failures were reported at 4 years or more, it is arcepted that an oil/alkyd primer topcoat system exposed in a severe climate can last 4 years or more. The responses compared to the time before the paint problem appeared was as follows: 19 at six munths or less, 13 at a year or less, 10 at two years or less, 9 at three years or less, 6 up to and over four years, and 6 responses were reported where the time was unknown. After a years time, 51 percent of the failures were apparent, 67 percent were apparent by two years and 81 percent were apparent by three years. Thus, if one established a time limit for a painting contract performance, a three year limit would probably sover a large majority of failures. 
The questionnaire responses also reported the frequency of painting at the Air Force bases. Most maintenance painting was on an "as necessary" basis while many bases painted on a three and four year cycle (See Figure 7). However, it may be noted that often a base would paint some of its steel structures "as necessary" but would maintain a periodic painting cycle for other structures.

\subsection{FIELD TRIP}

A field inspection trip was made April 17-20, 1978 by the authors and Harold Stevens, Air Force Civil Engineering Center, to Patrick AFB, Mac Dill AFB, Tyndall AFB, and Eglin AFB to examine corrosion and paint problems on steel.

These bases had responded to our questionnaire that coating/corrosion problems were extensive (see Figure 1). It may be noted that these bases were all in the $\mathrm{Ca}_{f}$ climate region and also were located close to a salt water marine exposure. A trip report was prepared and based upon our observations, the following summary was made:

- Overall, although the coatings procedures used at the bases we inspected have maintained the appearance to the ferrous substrate inspected, it was evident that corrosion protection has been a continuing problem at the bases.

- Sandblasting or other similar techniques to remove old paint to the substrate has not been a widely used method of surface preparation. As a consequence, the average coating thickness on steel appears to be increasing and this portends future coating problems.

- High performance coating, e.g., vinyls, as well as coatings best suitable for rural exposures, e.g., oil-alkyds, have both been used to protect the same types of steel structures on the same base.

- Often at a base, the coatings used for exterior surfaces of fuel tanks differed from those used for the exterior surfaces of water tanks or other structures even though exposure conditions and the steel substrate would both be the same.

- The extensive falling rust of the steel interior surfaces of hangars appear to present an increasing problem with the potential of interference with the hangar's function as a work and storage area.

- The lack of paint inspection personnel at the time of maintenance is likely to have contributed to premature coating failures on steel. The need for more inspection personnel was cited by all Base maintenance personnel as a problem at all bases. 
Photographs were taken during the field inspection trip and on related trips to Dover AFB and Seymour Johnson AFB. Selected photographs and related commentary are summarized by the type of structure involved rather than by chronological order of the inspection trip. These follow in the order illustrated in Figure 3 , $i . e$. , water towers, smoke stacks, galvanized steel, structural steel, fuel tanks, antennas and communication towers.

Water towers were inspected at each base and each tower had coating/ corrosion problems. At Patrick AFB, a water tower about to be demolished was examined. Another water tower that was undergoing extensive repair (Figure 8,9,10\&11), and one that had just been painted (Figure 12) were also examined. Typically, an oil/alkyd primer topcoat system was used. Over the years, extensive corrosion of the steel was apparent as the steel stud at the base of the recently painted water tower (Figure 13) indicates. The design of the anchorage of the water towers was typical of older units, since a tower at Tyndall AFB which was erected in 1941 and repainted last in 1976 had accumulated dirt and mildew and was rusting in the same general area (Figure 14). At Mac Dill AFB, a water tower was inspected which had been white metal blast cleaned before applying a zinc rich inorganic primer and a vinyl topcoat. The time interval between application of the primer over the blast cleaned surface was 3-4 hours and the surface preparation had been closely inspected. This water tower is in excellent condition after 6 years exposure (Figure 15). A new riser had been installed a year ago and the tie rods had some rust areas at the bolt ends due to mechanical damage to the coating. At the same base, a water tower had just been repainted a few months ago and painting of this tower was on a 2-3 year cycle. Surface preparation was by scraper and wire brush and an oil, alkyd primer/topcoat system was used.

While most of the problems of water towers were concerned with exterior surfaces, Eglin $A F B$ had a problem with interior surfaces with a vinyl system (VR-3) which had failed in the water storage area. However, inspection of the riser interior which had been painted at the same time with the same material, indicated no failures (Figure 16). We surmise that inspection of the surface preparation and application of the material within the tank area contributed to the premature failure.

Heat resistant coatings on smoke stacks or heaters were not insperited during our visit to the Florida bases, but we had inspected these types of structure previously and in particular the power plant at Dover AFB as part of this project. Previously, six bases had reported on the questionnaire that they had corrosion problems with steel exposed to high remperatures. Coatings used for these applications are generally exposed in a polluting environment, exposed to extreme temperature cycling, and often require high temperature cure to perform effectively; any of which may explain the continuing problems of protecting the steel substrate. Also, Dover AFB is experimenting with a proprietary zinc rich epoxy polyamide system with only limited success. Figure 17 illustrates the rusted stack and the proprietary coating at the base. 
Galvanized steel examined on the inspection trip consisted mainly of exterior surfaces of hangars, nose docks, and other buildings, fencing, conduits, and rallings. Frequently, the building's exterior cladding consisted of a factory-applied asphalt-asbestos coating on galvanized steel or simply painted galvanized steel. Often, the asphalt-asbestos coatings were badly alligatored while the galvanized steel substrate was still in excellent condition. Figure 18 illustrates a coating failure on galvanized steel cladding where the galvanized steel substrate is in good condition. Figure 19 illustrates a galvanized steel nose dock at Patrick AFB where the exposed uncoated galvanized fasteners on the ocean side appeared to be more corroded than those facing inland. In this regard, one of the hangars at Mac Dill AFB had some replacement panels fastened with vinyl coated fasteners which were performing well. At Mac: Dill AFB, a series of nose docks of galvanized steel cladding had been cocooned in 1966-67. Apparently, the cocooning operation consisted of taping fiberglass fabric over the joints, applying a blue wash primer (MIL-P-15328?) and an elastomeric coating (19-23 mils). The coating was delaminating off in sheets and exposing the galvanized steel substrate (Figure 20,21). As might be expected most of the failures were observed on the roof decks. Interestingly, the elastomeric coating was still flexible. A typical failure of the galvanized steel cladding was observed at Dover $\mathrm{AFB}$ at the cladding-concrete masonry block interface where the sealant used entrapped and accelerated rusting (See Figure 22). Respondents to the questionnaire often cited problems with conventional hangar doors and other overhead flexible doors on buildings. These doors are moved frequently on tracks and are also subject to mechanical damage. Most of the doors examined were either hot dip galvanized or electroplated zinc. The doors are painted not only for appearance but also for safety coding. Failures appeared to be caused by mechanical damage, lack of pretreatment primer, adequate surface preparation or poor application techniques. Photographs (Figures 23, 24) taken at Tyndall AFB show the hangar doors painted in 1976. Rust seemed to be breaking through in many painted areas and the doors had not been completely painted near where they overlapped other doors creating a rusting condition. Also at Tyndall AFB, galvanized railings on communication towers were observed to have paint failures which was attributed to the paint applied being apparently an iron oxide primer (TT-P-57) with no topcoat or wash primer pretreatment application.

Structural steel examined on the inspection trip consisted primarily of the interior supporting members of hangars, nose docks, etc. and also some exterior cladding (Figures 25, 26). An exhibit of rockets and missiles at Patrick AFB was extremely interesting, historically. While not directly related to the purpose of the trip, the coating/corrosion problems of the steel supporting structures detracted from the appearance of the exhibit (Figure 27). Inspection of hangar interiors generally revealed extensive rusting of the supporting structure. At Mac Dill AFB, daylight could be seen through rust holes in the roof. The interior structural members were rusting so as to a degree that the airmen complained that rust removal from equipment and parts bins was a daily necessity before work operations could start (Figure 18). 
The fuel tanks inspected at each base were in general, well maintained, although in the questionnaire response, fourteen bases had reported problems with fuel tanks coatings. One of the examples of proper maintenance painting was observed at the fuel tank farm at Patrick AFB (Figure 29). Five years ago, the tanks had been excavated from underground, placed on concrete "saddles" and recoated. The coating procedure involved white metal sand blasting, application of filler to the areas between tank and saddle, priming the tank with zinc rich inorganic coating and coating with a gloss vinyl enamel topcoat. Asphalt roofing felt was placed on the saddle to cushion the weight of the tank. The only rusting observed was in the saddle area, apparently from a delamination of filler and water absorption into the asphalt roofing felt (Figure 30). The coating system was adhering well even to areas where the steel had been badly corroded from previous underground exposures (Figure 31). At Mac: Dill $A F B$, the fuel tank farm was inspected and rusting appeared more extensive in this area than at other parts of the base. Painting was said to have been on a two- to three-year cycle using scraper and wire brush surface preparation and an o1l/alkyd primer topcoat system. Chalking on the tank exteriors was much in evidence as seen by staining of the black skirting at the base of a number of tanks. We also inspected the interior of one tank which was being abrasive blast cleaned prior to the application of an epoxy coating to the bottom portion of the interior. The fuel tanks observed at Tyndall AFB were in good condition with one minor exception. A sealant bond at the tank-concrete base interface had failed and water evidently had been entrapped since there was some rusting in this area.

In February, 1978, the fuel tanks at Seymour Johnson AFB were inspected for of premature fallures and because of the interesting type of failure it is included in this report. The coating system used was red lead primer, TT-P-86, and alkyd topcoat, TT-E-489, and paint was applied during the period of October 15, 1974 to November 1974. In December 1975, base personnel took photographs of extensive intercoat adhesion failures on two of the tanks. These failures were located on the north and northwest sides of the tanks (See Figure 32). During our inspection, ice $(1 / 4 \mathrm{inch})$ was scraped off in the area of the intercoat adhesion failures; the ice remained during the day of our inspection. Since the primer coat had not failed and primer topcoat resins were compatible, it is possible that the topcoat was applied to a cold damp surface. It is known that certain combinations of surface temperatures, ambient temperatures, surface moisture and dew point can often cause premature paint fallure.

The communication towers inspected at Tyndall AFB were perhaps atypical with regards to coating/corrosion protection. One tower appeared to be painted with only an iron oxide primer, TT-P-57, whether on structural steel members or the galvanized steel ralling. Another tower had a zinc chromate primer, TT-P-645, as a coating with a white spray paint application at the welded joints. Also, some fasteners at the base were cadmium plated steel while others were rusting steel (See Figures 33-36). 


\section{INTERIM COATINGS GUIDE SPECIFICATIONS}

One objective of this report was to prepare an interim guide specification. The responses and interpretation of the questionnaire sent to the Air Force bases and the field trip provided valuable background information relating to the potential requirements in a coatings guide specification. For example, the responses to the questionnaire indicated that 81 percent of the coating/ corrosion problems were apparent within three years and thus, a three year performance guarantee would cover most problems. Poor surface preparation and poor quality of coatings were cited by the questionnaire responses and by observation during the field inspection as the predominant cause of coating/corrosion problems. These problems have persisted in Air Force structures despite the availability of Steel Structure Painting Council (SSPC) procedures for surface preparation and recommendations for coating systems for different environments in the Paints and Protective Coatings manual, AFM 85-3. It is apparent that the guide specification would benefit from having the contractor prepare test panels for both surface preparation and the coating system which would have to be approved by the contracting officer before work is initiated. Many of the problems occurred with the use of oil, alkyd primer/ topcoat systems. The use of high performance coating systems would be advantageous even though their use might be considered overdesigned for some environments. Also, restricting the coating system choices should allow less chance for selection error by the specifier. It was further apparent that the quality control of coatings used could be improved by a testing requirement when using 20 gallons of paint instead of the 50 gallon minimum requirement most commonly used (see Fed. Test Method Std. No. 141). Also, it is apparent that inspection must be improved and that, for this purpose, photographic records and selected inspection tools would greatly assist the inspector. Each base should have a full complement of inspection tools available to the inspector to control the complete operation from surface preparation to coating application.

Meetings were held with Air Force personnel associated with the project to develop an interim guide specification. The model protective coating specification, SAC Regulation 85-5, Protective Coatings, was used as the model for the specification. The proposed specification (see Appendix B) includes a number of innovative clauses and these are numerated as follows: required prebid conference; 3 year guarantee of workmanship; paint testing where an excess of 20 gallons is used; contractor can add 5 percent to contracts up to $\$ 10,000$ and then add up to $\$ 300$ for each type of coating used for contracts over $\$ 10,000$ to cover testing costs; contractor to provide inspection equipment; the inspection record shall contain a photographic record of surface preparation and paint application; test panels for both surface preparation and paint application; the requirement that the exposed ferrous substrate be primed no longer than 8 hours after cleaning and in no circumstances that the exposed surfaces be left overnight; and the complete coating system be furnished by one manufacturer. 
Since the potential specific qualified paint materials are still undergoing laboratory and field test exposures, the materials listed in the draft painting schedule are for informational purposes only. The final model specification is expected to include recommended coating thicknesses and product designation information.

\section{SUMMARY}

A questionnaire relating to coating/corrosion problems on steel and galvanized steel surfaces was developed and sent to 127 Air Force bases. Eighty eight bases responded and the responses were analyzed for 1 ) the types of structure involved, 2) surface preperation, 3) coating system used, 4) time before the problem appeared, and 5) the painting r:ycies commonly used by the Air Force bases. Based upon the questionnaire results, field inspections, were made at Patrick, Mac Dill, Tyndall and Eglin Air Force bases where coating/currosion problems were reported as extensive.

The following statements summarize the questionnaire responses and the inspection trip observations:

- Corrosion protection has been a continuing problem at Air Force Bases. For example, the extensive rusting of the interior steel support structures of hangars appears to increasingly interfere with the hangar's function as a work and storage area.

- Most of the problems reported and observed were with maintenance coating failures on steel structures.

- Standblasting or other similar techniques to remove old paint to the substrate has not been a widely used method of surface preparation. Paint typically is applied to layers of old paint and, as the average coating thickness on steel is increasing, so is the potential for future coatings problems.

- Periodic painting cycles involving steel structures appeared to be mostly 3-4 years. However, structures were frequently painted "as necessary".

- The use of high performance coating systems had not been prevalent at Air Force Bases, regardless of the severity of the environment. Where these coating systems have been used, they have been performing well. Often, high performance coatings, e.g., vinyls as well as coatings best suitable for rural exposures, e.g., oil. alkyds, have both been used to protect the same types of steel structure on the same base.

- The lack of uniforn paint testing procedures or paint inspection personnel and inspection guides is likely to have contributed to premature coating failures on steel. 
An interim guide specification was developed, using SAC Regulation 85-5, Protective Coatings, and the questionnaire results and inspection trip observations for guidance.

\section{ACKNOWLEDGEMENTS}

The authors wish to thank the following persons for their helpful advice, encouragement and assistance: Harold Stevens, Tyndall AFB, LT Robt. Gunning, Tyndall AFB and Johnny Davis, SAC, Offutt AFB. Also, the authors wish to thank all the Air Force Base personnel who provided response to the questionnaire sent and the base personnel at Patrick, Mac Dill, Tyndall and Eglin Air Force Bases who provided valuable guidance and discussion on coating/corrosion problems.

\section{REFERENCES}

[1] L. H. Bennet, et al. "Economic Effects of Metallic Corrosion in the United States, Part I," NBS Special Publication 511-1, Superintendent of Documents, U.S. Government Printing Office, Washington, D.C. 20402 (May 1978).

[2] G. H. Payer, et al. "Economic Effects of Metallic Corrosion in the United States - Appendix B, Part II," NBS Special Publication 511-2, Superintendent of Documents, U.S Government Printing Office, Washington, D.C. 20402 (May 1978).

[3] H. Stevens, AFCEC/DEM, Private Communication

[4] C. Hahin, "Corrosion Costs of Air Force and Army Facilities and Construction of a Cost Prediction Model," CERL Technical Report M-224, July 1977

[5] G. T. Trewartha, "An Introduction to Weather and Climate," 2nd Ed., McGraw-Hill Book Co. Inc., New York, 1943.

[6] J. D. Keane, Ed., "Steel Structures Painting Manual, Volume 2, Systems and Specifications," Steel Structures Painting Council, Pittsburgh, PA 15213 (1964). 


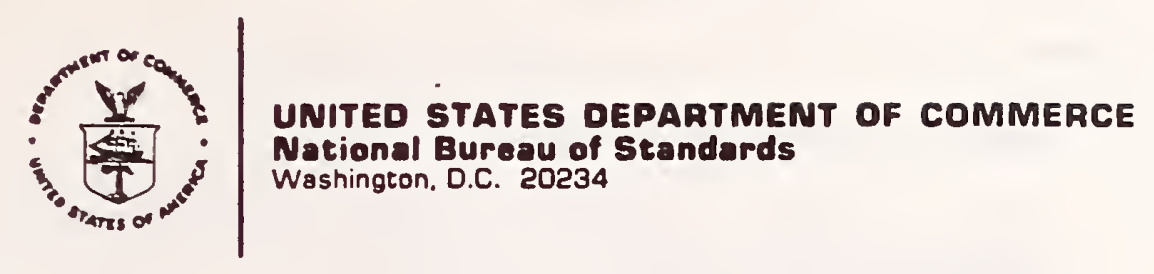

November 15, 1977

Dear Sir:

The enclosed questionnaire is intended to obtain information about present problems with coatings on steel at Air Force bases. Information from completed questionnaires will assist us in developing new Air Force specifications for long-service protective coatings for steel. The development of these specifications will be done by the National Bureau of Standards under the sponsorship of AFCEC/DEM and CEEDO/CN.

The questionnaire is in two parts. Part A concerns background information about your base. Part B concentrates on one or more significant problems of coating failure or corrosion. Please complete the questionnaire to the best of your knowledge and return it to

\author{
Dr. Paul Campbell \\ National Bureau of Standards \\ Bldg. 226, B-348 \\ Washingt on, D.C. 20234
}

Verbal clearance for this voluntary questionnaire has been given by Mr. John Webster of the General Services Administration.

Your cooperation in giving us this information is appreciated. Please telephone me at 301/921-3441 (users of AUTOVON can reach this number by requesting it after dialing AUTOVON 227-1201).

Sincerely,

$$
\text { Pcuel r Camprell }
$$

Paul G. Campbel1

Research Chemist

Materials and Composites

Section

Structures, Materials and

Safety Division

Center for Building Technology,

IAT 
PART A -- GENERAL INFORMATION

(Please fill in, or check appropriate blank)

1. NAME OF INSTALLATION

2. LIST, IN ORDER OF PRIORITY, PREDOMINANT COMPLAINTS AT YOUR INSTALLATION CONCERNING THE PROTECTION OF STEEL:

3. IF YOU HAD A CHOICE (DISREGARDING COST) OF PAINT TO USE IN PROTECTING STEEL, WHICH PAINT WOULD YOU USE

4. WHAT PAINTS DO YOU PRESENTLY USE FOR THE PROTECTION OF STEEL

5. IS PAINTING DONE BY BASE PERSONNEL OR BOTH THROUGH PRIVATE CONTRACT

6. IS THERE A SCHEDULE FOR PERIODICALLY REPAINTING BUILDINGS OR ARE BUILDINGS REPAINTED AS IT IS NECESSARY ?

7. IF THERE IS PERIODIC REPAINTING, HOW OFTEN IS IT DONE ?

8. HOW WOULD YOU DESCRIBE THE CLIMATE (OR ENVIRONMENT) OF YOUR BASE

9. DO YOU HAVE ANY COMMENTS ABOUT COATING PROBLEMS ON METAL AT YOUR BASE? 
10. [To be completed by respondent (please print)]

NAME

ADDRESS

TELEPHONE NUMBER (please include area code, exchange and extension rather than Autovon number)

* If the enclosed self-addressed envelope is lost, please return completed questionnaire to**

Dr. Paul G. Campbell

Room B-348 Building Research

National Bureau of Standards

Washington, DC 20234

Telephone: 301-921-3441 
PART B -- SPECIFIC PROBLEM WITH THE PROTECTION OF STEEL

(Please fill in, or check the appropriate blank.)

1. NAME/NUMBER OF STRUCTURE; NATURE OF THE PROBLEM:

2. USE AND APPROXIMATE AGE OF THE STRUCTURE:

3. EXPOSURE CONDITIONS OF STRUCTURE WHERE THE PROBLEM OCCURS:

4. PHYSICAL DESCRIPTION OF STRUCTURE:

SURFACE FINISH OF STEEL: STRUCTURAL (ROUGH)____; SMOOTH____ OTHER TYPE OF STEEL: GALVANIZED_____ AFTER RE-PAINTING

5. COATING PROBLEM: WITH INITIAL COATING ; AFTER RE-PAINTING

FACTORY-APPLIED ; TYPE OF COATING

PAINTED ON-SITE ; BY BASE PERSONNEL ; BY CONTRACT TYPE OF COATING COMMENTS

6. SURFACE APPEARANCE OF PROBLEM AREA: chalking ; blistering peeling___ loss of adhesion___ rusting ; color change gloss change ; alligatoring ; staining ; mildew

7. HOW SOON AFTER PAINTING DID THE PROBLEM APPEAR 
HAND CLEANING

BRUSH-OFF BLAST

COMMERCIAL BLAST

NEAR WHITE OR WHITE/METAL BLAST

OTHER

9. PAINT USED (MARR (A) FOR INITIAL PAINTING, (B) FOR RE-PAINTING, IF RNOWN):

PRIMER（SPEC. NUMBER(S)）

1. OIL

2. OIL-ALKYD

3. ALKYD

4. PHENOLIC

5. VINYL

6. CHLORINATED RUBBER

7. INORGANIC

8. OTHER

9. NOT USED
TOPCOAT (SPEC. NUMBER (S))

10. OIL

11. ALKYD

12. SILICONE-ALKYD

13. PHENOLIC

14. VINYL

15. CHLORINATED RUBBER

16. URETHANE

17. EPOXY

18. OTHER

10. COMMENTS: 
APPENDIX B

INTERIM SPECIFICATION FOR PAINTING OF HIGH VALUE STEEL STRUCTURES

\author{
PREFACE
}

$i$ Use this model specification in the preparation of contract specifications for coating high value steel structures. Do not make it part of the contract merely by reference; copy pertinent portions into the contract documents.

ii Notes are included in this model for the information of the designer and specification writer. Do not include these notes in the contract specification.

iii Information in parentheses () is included for clarification or to indicate options required to tailor this model to fit the individual project. Delete provisions not applicable to the project and remove parentheses before typing the contract specification.

iv This model specification is considered appropriate to the coating/ painting of new construction surfaces or the recoating/painting of previously coated surfaces. The important difference being that of preparing the surface to receive the specified coating. The performance requirements of all steps must be fully qualified.

$v$ A prebid conference is required for high value steel structures where the area to be painted is greater than $50,000 \mathrm{ft}^{2}$ or the contract costs are expected to exceed $\$ 50,000$. The type of structures covered by this specification include communication towers, hangars, potable water towers, fuel tanks, etc. At this conference, the details of the specifications will be explained in detail, including the work certification clause and a three year guarantee of workmanship. In the event the low bidder has not attended the prebid conference, he shall sign a statement that he has read and understood the provisions of the specification. 


\title{
PROTECTIVE COATINGS
}

\section{SECTION I}

\author{
GENERAL
}

1.1 DESCRIPTION. These specifications and associated drawings provide details and performance requirements for materials surface preparation, and finish application necessary to this protective coatings project. The term "coating" as used, includes (emulsions) (enamels) (paints) (lacquers) (varnishes) (sealants) (fillers) and other coatings whether used as prime, intermediate, finish or single application. The contractor will furnish all (as applicable) paint, supervision, labor, equipment, and materials to execute and satisfy the requirements of this contract as hereinafter detailed and described.

The work to be performed under this contract consists of (washing) (repairing) (abrasive blasting) (water blasting) (rotomblast) (scraping) (solvent cleaning) (steam cleaning) or other methods of rust or deteriorated paint removal, as applicable, and other operations necessary to prepare a surface for protective coating application. Facilities making up this contract consist of

NOTE 1: Structural repairs needing correction prior to paint application are to be identified and included as separate bid items. Technical provisions covering significant repalrs are to be included under a separate section of these technical provisions.

NOTE 2: If minor structural repairs cannot be performed in-service prior to painting, identify the scope of repalr required as part of the painting technical provisions.

NOTE 3: On each painted structure, on the corner of the same wall as the building number and located at the lower edge of the painted surface, a stencil (approximately $6 \mathrm{in}^{2}$ ) shall be made. It shall contain the following information:

Contractor:

Paint System (Fed/or Mil Speciflcation(s))

Date of Application:

Paint Manufacturer 
1.2 LOCATION. Contract to be performed at $A F B$ on

all

(buildings, structures, facility, or utility) as shown on the site plan drawing

1.3. TECHNICAL SECTION. The following section of these technical provisions and associated drawings describe work to be performed. The contractor is responsible for determining the appropriate division of work where subcontractors are involved.

\section{SECTION}

1. General

2. Structural Repairs (welding - sheet metal - etc.)

3. Cleaning, Preparation, and Pretreatment of Surfaces.

4. Application

5. Painting Schedule

6. Color Schedule

7. Measurement for Payment (Where Applicable).

1.4 SUPERVISION. Competent supervision shall be provided by the contractor at all times when work is in progress. The contractor or his supervisor shall coordinate and schedule contractor effort and insure that work accomplished and materials used are in conformance with technical provisions and drawings. The contractor or his supervisor shall note discrepancies and disparities in drawings, technical provisions, and other instructions and present them to the contracting officer in writing for correction and clarification.

1.5 CONTINUED USE OF FACILITIES (IF APPLICABLE). (Buildings) (structures) (facilities and utilities) will continue in use during this contract. Work and work areas shall be scheduled (at least 24 hours) in advance of anticipated time of accomplishment. Work shall be performed in a manner to create minimum disturbance and inconvenience to occupants. Contractor personnel will be limited to work areas.

1.5.1 Work Schedule. Working hours for the contractor will normally be between the hours of _._AM and_PM excluding Saturdays, Sundays and Federal holidays. If the contractor wishes to work during periods other than above, additional Government inspection forces will be required. The contractor must notify the Contracting officer sufficiently in advance (minimum 24 hours) of his intention to work during other periods to allow assignment of additional inspection forces when the Contracting 
Officer determines that the additional inspection force is reasonably available. If such force is reasonably available, the Contracting Officer may authorize the contractor to perform work during periods other than normal duty hours/days; however, if inspectors are required to perform in excess of their normal duty hours/days primarily for the benefit of the contractor, the actual cost of overtime inspertion will be charged to the contractor and will be deducted from the final payment of the contract amount.

1.6 CONTRACTOR-FURNISHED OPERATING EQUIPMENT. The contractor shall (provide/furnish) all equipment necessary to accomplish the contract. Power equipment shall be equipped with safety, noise-limiting and fume control devices, and shall be in a safe and efficient operating condition. Only qualified operators shall be permitted to operate the equipment.

1.7 CONTRACTOR-FURNISHED INSPECTION EQUIPMENT. The contractor shall (provide/furnish) all equipment necessary for the inspection of work covered by the contract as specified in 1.14 .6 .

1.8 APPLICABLE STANDARDS, PUBLICATIONS, SPECIFICATIONS AND TECHNICAL DESCRIPTIONS. Unless specifically exempted by this specification and drawings, all work accomplished under this contract shall conform to the most recent standards and codes established by the following publications:

1.8.1 Federal Standards

No. 141 and Change

No. 595, A and Change 1, 2 June 1968

1.8.2 Department of Defense

MIL-STD-101

MIL-STD- 161

1.8.3 0thers

1.8.4 Federal Specifications
Methods for inspection, sampling and testing of paint, varnish, lacquer, and related materials.

Color.

Color Code for Pipelines and for Compressed Gas Cylinders.

Identification Methods for Bulk Petroleum Products Systems Including Hydrocarbon Missile Fuels.

Steel Structure Painting Council, Painting Manual, Vol. 1 and 2 .

(List applicable specifications) 
NOTE: Specify the most up-to-date edition of each specification and only the family of coatings intended for use.

1.9 MATERIALS. Materials shall conform to the requirements of the specification shown in the paint schedule and the requirements herein. Paints shall be in sealed, unbroken, containers that plainly show the designated name, formula or specification number, batch number, Fed Std 595 color, date of manufacture, manufacturer's instructions and name of manufacturer. Paints shall be furnished in containers not larger than five-gallon capacity. Materials shall be homogeneous and show no separation that cannot be overcome by stirring, and when mixed shall permit application by brush, roller, glove or airless spray methods. Paints stored more than 12 months shall not be used. All materials furnished will be subject to specified testing.

\subsection{SAMPLES AND TESTING:}

NOTE: Testing is required for quantities of paint in excess of 20 gallons or where the sensitivity or critical aspects of the area in which work is to be performed necessitates testing of coating material of a lesser value. The value of each product to be used under the paint contract will be estimated by the project designer or specification writer. The latter information and items to be tested will not be disclosed to the contractor. For 20 gallons or less, the factors of time, value of material versus cost of testing, and the end use of the material may justify acceptance on the basis of test reports furnished.

1.10.1 Contractor-furnished paints and painting materials proposed for use shall be stored at the project site or in an area and manner acceptable to the contracting officer or his representative (See 1.11) Sample containers shall be sealed and labeled.

NOTE: Allow 30 days for testing of paint materials.

After paint materials are received or placed in storage, the contractor in the presence of the contracting officer or his representative shall take a one quart sample of each batch by random selection of sealed containers. Samples shall be clearly identified by designated name, specification number, intended use, and quantity in gallons involved. The Government will ship and test the samples. The contractor shall add 5 percent to the contract bid for contracts up to $\$ 10,000$ to be set aside for paint testing. The contractor shall add $\$ 300$ for each type of primer/paint to the contract bid for contracts over $\$ 10,000$ to be set aside for paint testing. A list of government laboratories i.s contained in the Directory, U.S. Government Inspection Services and Testing Laboratories, July, 1976, General Services Administration, Federal Supply Services. Superintendent of Documents, U.S. Government Printing office, Washington, D.C. 20402. The first test will be paid 
for by the contractor using the 5 percent set aside for paint testing. Where a sample fails to meet specification requirements, the contractor must take all necessary action to reprepare the surfaces painted with material represented by the sample which failed testing and apply an acceptable coating. The expense of retesting will be deducted from the payments due the contractor at the actual cost for each sample tested.

1.10.2 Overseas Samples and Confirmation Testing. The contractor shall furnish either of the following for all batches of paint proposed for use.

1.10.2.1 A certified test report showing that batch proposed met all specification requirements.

1.10.2.2 A certified test report showing that a previous batch manufactured using the same formulation as that used in manufacturing the batch proposed met all specification requirements and a report showing test results on the batch proposed for the following properties for which there are requirements in the material specification: Weight per gallon, viscosity, fineness of grind, drying time, color, gloss, etc.

\subsection{STORAGE FACILITIES:}

1.11.1 Contractor-furnished material and equipment must not be stored in work area. The Contracting officer or his representative will assign the storage area and will approve the contractor supplied storage shed.

1.11.2 Storage of Contractor-Furnished Painting Materials (If Applicable). Paint materials shall be stored at site in an approved contractor furnished building of size to contain all painting materials and be capable of maintaining $50^{\circ} \mathrm{F}$ temperature, minimum. Windows, if any, shall be permanently secured and the one door must have two hasps. The contractor and Government will, each, provide a lock and five keys. All painting materials upon receipt shall be place in previously described storage facility. Specified security method insures that painting materials can be stored, sampled, and removed for use only when both contractor and contracting officer or his representative are present.

1.11.3 Storage of Building or Facility Appurtenances (If Applicable). Contractor shall provide secure safe storage for all items removed from structures during preparation and painting operations. Provisions shall be made to protect all items from loss or damage from weather, vandalism, and other causes. Items shall be labeled and stored immediately after removal from installed locations. Contractor shall note and call the attention of contracting officer or his representatives to all damaged intalled items. All items or building components damaged or lost as a result of contractor operations shall be repaired or replaced at no cost to the Government. Removed items shall be reinstalled as part of this contract. 
1.11.4 Hazardous Material. Broken glass and other hazardous material resulting from preparation or painting operations shall be removed immediately to disposal area.

NOTE: Disposal area and distance to area must be shown on site location drawing.

\section{1,12 INSPECTION :}

1.12.1 Contractor shall accomplish work in an orderly progression of steps to satisfy the performance requirements of this specification. The following items of work will be considered steps or phases: repair, cleaning, surface preparation such as filling, smoothing, removal of scale or old paint, application of sealer, application of prime, and the separate application of subsequent coats.

1.12.2 Contractor shall anticipate the completion of each step or phase and schedule the inspection of the phase by contracting officer at least eight hours in advance to preclude possibility of delay.

1.12.3 Contractor shall not initiate or commence on any subsequent step or phase until previous phase has been approved by contracting officer as satisfying specification requirements for that phase.

1.12.4 Any material applied by the contractor to a subsequent phase before receiving contracting officer approval of a prior phase shall be corrected by removing applied material. In addition, the contractor shall perform all work required for earlier phases and secure required approvals, at no cost to the Government.

1.12.5 Completed area or items shall be scheduled for final inspection within 72 hours of time of completion. Deficiencies shall be corrected within the 24 hour period or three workdays following the scheduled final inspection and rescheduled for inspection.

1.12.6 The Government may use any or all of the following equipment or comparative standards and samples in field testing and inspecting the work to affirm compliance with contract requirements. The contractor shall have available the inspection equipment and comparative standards. Calibration standards and instructions for use will also be furnished. The equipment to be furnished consists of (Polaroid camera), (wet film gages), (dry film gages), (surface thermometers), (wet and dry bulb thermometers or portable psychrometer), (surface profile gages), (holiday detectors), (20 power magnifying lens), (viscometers).

1.12.7 Kandoin samples will be taken from painter's buckets or from spray nozzle and tested for weight per gallon, viscosity, fineness of grind, hiding, etc. When a sample fails to meet specifications, the material represented by the sample will be removed and replaced at no cost to the Governinent. 
1.12.8 Film thickness tests will be taken on a random basis on all surfaces painted. When surfaces tested do not meet film thickness specifications, the wall or $400 \mathrm{sq}$. foot area, whichever is less, shall be repainted at no cost to the Government. (Include if applicable: Damage incurred through destructive testing such as dry film thickness tests shall be repaired or touched up at no cost to the Government.)

1.12.9 Photographs taken after surface preparation, during application, and after completion of painting are to be considered part of the inspection record. They are to be signed, dated by the inspector and contractor with a brief descriptions of the picture contents.

1.13 GUARANTEE. The contractor will furnish a written guarantee which will unconditionally guarantee the new coating to be free from any physical defect or deterioration which would affect its functional performance for a period of three years from the date of final acceptance of the contract work. Defects will be repaired or replaced by the contractor to the satisfaction of the contracting officer as often as necessary throughout the period of the original guarantee. During the guarantee, the contractor shall not be held liable under the terms of the guarantee for:

a. Any damage to the coating caused by failure of the painted structure.

b. Any damage to the coating caused by abrasions or abuse from unforeseen causes beyond the control and without fault or negligence of the contractor.

c. Any damage caused by fire, lightning, or act of public enemy.

1.14 WORK CERTIFICATION. Upon completion of the work and prior to final payment of the contract, the contractor and the coatings manufacturer will furnish the contract officer a certification signed by both the manufacturer and the contractor that the surface preparation and coating installation was in no manner deleterious to the performance of the coating. Any cost for the coating manufacturer to supply inspection, certification, etc., will be included in the contract bid.

1.15 PAYMENT. No separate payment will be made for the work covered under this section of the specifications and Pretreatment of Surfaces, and all costs in connection therewith shall be included in the lump sum contract price for the entire work to be performed under this contract. 


\section{SECTION 2}

\section{CLEANING, PREPARATION, AND PRETREATMENT OF SURFACES}

2.1 GENERAL. Painting operations shall not begin until surface has been conditioned or prepared to receive protective coating by contractor and then inspected and approved as ready for application of coating by contracting officer or his representative and the coatings manufacturer.

Surfaces to be painted shall be clean before applying paint or surface treatments. $0 i 1$ and grease shall be removed with clean cloths and cleaning solvents before mechanical cleaning. Cleaning solvents shall be of low toxicity and shall have a flashpoint in excess $100^{\circ} \mathrm{F}$. Solvents, thinners, and mineral spirits will conform to Los Angeles Rule 442 or other applicable NIOSH standards.

NOTE: See air pollution criteria for volatility of solvent.

Cleaning and painting shall be so programmed that dust and other contaminants from the cleaning process will not fall on wet, newly painted surfaces. Drips, runs, and irregularities in the existing or previously applied coating shall be made smooth before application of coating. Plants, shrubs, and vines growing along structural foundations or fastened to buildings will be loosened and laid back until the paint is dry and then refastened. The workmen must protect all plants. Contractor's protective interior and exterior coverings must be removed after each space or area is painted and at the end of each day, if the space is in use.

2.1.1 (When Applicable). Items not previously painted or listed as "items not to be painted" shall be removed and placed in secure storage for later replacement in original location or will be protected by masking or drop cloths.

2.1.2 (When Applicable). Exposed radiators and heating or cooling units shall be temporarily removed to facilitate painting of otherwise inaccessible surfaces.

2.1.3 (When Applicable). Screws, and other fasteners shall be removed from surface to be painted and holes shall be repaired and made ready for painting.

2.1.4 (When Applicable). Removal and reinstallation of building or structural items shall be accomplished by workmen skilled in the crafts involved.

NOTE: For ferrous material select and use completely the appropriate surface preparation or cleaning method recommended by AFM 85-3, AFM 88-15, Steel Structures Painting Manual, or other competent authority. An alternative is the section detailed below. 
Ferrous surfaces that have not been' shop-coated shall be solvent-cleaned to remove oil and grease. Surfaces that contain loose rust, loose mill scale, and other foreign substances shall be mechanically cleaned, or sandblasted. After cleaning, one coat of ferrous metal primer shall be applied to ferrous surfaces to receive paint not to exceed 8 hours after the surface preparation operation. In no case, shall the unprimed substrate be left uncoated overnight. Contractors will abrade only that area that can be coated in the same work period.

2.1.5 All dirt, rust, scale, loose rust, loose mill scale, welding flux and slag, oil and grease, and other detrimental matter which may impair adhesion of the coating shall be removed.

2.1.6 All loose, cracked, brittle, nonadherent paint shall be removed in cleaning unless it is otherwise specified. Where the remaining paint is excessively thick, all exposed edges shall be feathered. Spot cleaning shall be conducted in a manner which will minimize damage to sound paint. Rust spots shall be thoroughly cleaned and the edges of all old paint shall be scraped back to sound material

2.1.7 When old painted surface is not to be removed completely, a high pressure water spray, 500 - 1500 psi, containing suitable rust inhibitor(s) shall be used to remove loose paint and dirt on the surface. Spot test painted surfaces to determine if coatings containing active solvents, e.g. urethanes, epoxies, will lift the old coating. If lifting occurs, do not apply the coating. The Contractor shall request the contracting officer to specify corrective action. However, any rust exposed during the cleaning process shall be removed by abrasive blasting.

2.1.8 The contractor shall have the right to remove all old paint from areas where the amount of damaged or loose paint is excessive.

2.1.9 Paint that curls or lifts after application of the spot or primming paint shall be removed and the area shall be repainted.

NOTE 1: There are four degrees of blast cleaning. See Steel Structures Painting Council (SSPC) Manual No. 2 or AFM 85-3, chapter 4, for greater detail.

NOTE 2: For special purpose coatings, surface preparation such as fuel oil tanks, dimeralized water tanks (AFM 85-3, chapter 10) use cleaning method outlined in AFM 85-3, chapter 4, or Steel Structures Painting Manual, volume 2 .

NOTE 3: Permit power tool cleaning in accordance with SSPC Preparation No. 3 where abrasive will damage adjacent surfaces or contaminate the adjacent equipment.

2.1.10 A test panel shall be prepared by the contractor to be used as a standard of surface preparation. The test panel shall be an approximately 4 feet by 4 feet section on the structure to be painted. The degree of 
surface preparation shall be approved by the contracting officer or his delegated representative before surface preparation is continued. Photographs of the cleaned and approved test panel shall become part of the inspection record and are to be signed, dated by the inspector and contractor with a brief description of the picture contents.

\subsection{NONFERROUS METALS}

NOTE: Aluminum, copper, and galvanized surfaces are not to be painted. However, where unusual conditions exist or can be expected to cause corrosion or deterioration of these materials specify surface preparation as follows. See To 1-1-2 for specific corrosion problems.

(Aluminum, aluminum alloy, copper, galvanized) surfaces shall be free of all corrosion products, loose and foreign material, and shall be solvent cleaned and treated with a vinyl type wash coat prior to primer and top coat application.

2.3 BLAST CLEANING. Painting schedule indicates the SSPC specification number to be used for blast cleaning. The painting schedule will refer to one or more of the following SSPC specification number(s).

$$
\begin{aligned}
& \text { SSPC-SP } 6 \text { No. } 6 \\
& \text { SSPC-SP } 10 \text { No. } 10 \\
& \text { SSPC-SP } 5 \text { No. } 5
\end{aligned}
$$

Commercial Blast Cleaning

Near-white Blast Cleaning

White Metal Blast Cleaning

In all of these procedures all the old paint is removed.

Compliance with surface preparation specifications Nos. 5 and 6 will be based upon those pictorial standards of SSPC-Vis 1, designated in Specification Nos. 6 and 5, respectively. The appearance of the surface after Near-white Blast Cleaning shall correspond with pictorial standards BSA $21 / 2, \operatorname{CSA} 21 / 2$, or DAS $21 / 2$ of SSPC-Vis 1 . Immediately after cleaning, specified primer coating shall be applied before any visible or detrimental rusting occurs. The work schedule will indicate when a pretreatment coating is required on steel. In this case, apply pretreatment before application of primer paint. Shop or field applied prime coated metal will be protected from corrosion during transit, before and after installation. Treat deteriorated areas immediately upon detection.

2.4 ELEVATED TEMPERATURES. Steel stacks and other surfaces subject to elevated temperatures shall be prepared for painting by use of SSPC-SP-1, Solvent Cleaning, followed by SSPC-SP-6, Commercial Blast Cleaning. The types of coatings used for these surfaces are indicated in the painting scheduled herein. 
2.5 PETROLEUM TANKS. Interior ferrous surfaces of petroleum storage ranks. The interior surfaces of tanks shall be thoroughly cleaned of dirt, oil, or grease prior to blast cleaning. 0il or grease shall be removed by the methods outlined in Steel Structures Painting Council Surface Preparation Specification SSPC-SP-l, Solvent Cleaning.

2.5.1 Folloiwng cleaning, the tank interior surfaces shall be dry sandblasted in accordance with the requirements of SSPC-SP-5, White Metal Blast Cleaning. After blasting, the tank surfaces shall be brushed and blown off with compressed air or cleaned by vacuum before application of the primer coating.

2.5.2 Since the primer should be applied as soon as possible after the blast cleaning, in no case shall the time interval exceed 8 hours. If any visible rusting does occur after blasting regardless of the time interval, the surface shall be reblasted prior to applying the primer. The sandblasting and application of the lining shall not be done when the steel surface temperature is less than $2^{\circ} \mathrm{F}$ above the dew point temperature of the surrounding air. This condition will most likely occur in underground tanks. For such cases, heated air shall be circulated through the tank as required to maintain this $2^{\circ} \mathrm{F}$ temperature differential, and thereby prevent condensation of moisture on the tank surface. 


\section{SECTION 3}

\section{APPLICATION}

3.1 GENERAL. The finished surfaces shall be free from runs, drops, ridges, waves, laps, brush marks, roller marks, and variations in color, texture, and finish. The coverage shall be complete, and each application shall be so applied as to produce film of uniform thickness. Special attention shall be given to insure that all surfaces including edges, corners, cracks, fissures, crevices, welds, and rivets receive a film thickness equal to that of adjacent painted surfaces. All fissues or openings in and previously painted surfaces shall be thoroughly filled and sealed by applied coating. Adjacent areas and installations shall be protected by use of drop cloths, or other approved precautionary measures. Lifting or raising of old paint by new application must be called to the attention of the contracting officer or his representative immediately by the contractor. Application of new coating shall cease until corrective action has been determined and implemented

\subsubsection{Test Panel. A test panel shall be prepared by the contractor to} be used as a standard for paint application. The test panel shall be an approximately 4 feet by 4 feet section of the structure to be painted. The same panel area used as a standard for surface preparation may be used as the substrate for paint application. The wet and dry film thickness and film continuity shall be tested as in 3.6.1. The paint application shall be approved by the contracting officer or his delegated representative before paint application is continued. Photographs of the approved panel shall become part of the inspection record and are to be signed, dated by the inspector and contractor with a brief description of the picture contents.

3.2 COATING PROGRESS. (Use only when more than one lamination is required.) Sufficient time shall elapse between successive coats to permit proper drying. This period shall be modified as necessary to suit adverse weather conditions.

\subsection{STORAGE, MIXING AND THINNING:}

3.3.1 General. At time of application, paint shall show no signs of hard settling, excessive skinning, livering, or other deterioration. Paint shall be thoroughly stirred and kept at a uniform consistency during application. Paints of different manufacturers shall not be mixed together. Where necessary to suit conditions of surface, temperature, weather, and method of application, packaged paint may be thinned immediately before application per manufacturer's instructions but not in excess of one pint of suitable thinner per gallon. Primer paint shall be thinned as necessary to insure wetting and penetration action.

3.3.2 Vinyl-type wash coating conforming to Military Specification MIL-P-15328 shall be mixed by adding one volume of acid component to four volumes of resin component. The acid component shall be added 
slowly with constant stirring to the resin component. After mixing, the wash coat shall be used within eight hours. If additional thinning is required to maintain a wet spray, reduction shall be made with normal butyl alcohol, or 99 percent isopropyl alcohol.

\subsection{ATMOSPHERIC CONDITIONS. Paints other than water-thinned coatings} shall be applied only to surfaces that are completely free of surface moisture as determined by sight or touch. In no case shall paint be applied to surfaces upon which there is visible frost or ice. While painting is being done, the temperature of the surfaces to be painted and of the atmosphere in contact therewith shall be at or above $45^{\circ} \mathrm{F}$. The application of the paint shall not be done when the steel surface temperature is less than $2^{\circ} \mathrm{F}$ above the dew point temperature of the surrounding air. A surface temperature thermometer will be used to check surface temperatures. During periods of inclement weather, painting may be continued by enclosing the surfaces with temproary shelters and applying artificial heat, provided the temperature requirements prescribed above are maintained. Unvented combustion type heaters will not be permitced.

\subsection{TIME BETWEEN SURFACE PREPARATION AND PRIMER PAINTING (see also} 2.1.4). Surfaces that have been cleaned, pretreated, or otherwise prepared for painting shall be given an application of the specified (pretreatment primer) material as soon as practicable after such preparation has been completed, but in no case exceed 8 hours. Where prepared surface has deteriorated, the surface conditioning process will be repeated to restore required surface. All prepared surfaces must be coated prior to the end of the work period when the base substrate was exposed.

3.5.1 Time Between Application of Successive Coats. The time between application of successive coats of paint over the primed substrate shall be not less than or exceed the paint manufacturer's directions.

3.6 APPLICATION METHODS. Paint may be applied by brushing, air spraying, airless spraying, or hot spraying or a combination of these methods. Daubers or sheep skins may be used when no other method is practicable for proper application in places of difficult access. Roller coat application may be used on flat or slightly curved surfaces or over blast cleaned or pickled surfaces or over primed surfaces. Unless specifically authorized, or unless the paint over such areas is subsequently brushed out, roller coat applciation shall not be used in application of primer over hand tool cleaned, power tool cleaned, flamed cleaned or irregular surfaces such as rivets, bolts, crevices, welds, corners, or edges. Irregular surfaces such as rivets, bolts, crevices, welds, corners or edges shall be coated with primer by brush application prior to main primer application. Dripping, or flow coating shall be used only when specifically authorized. Special provisions for spectfic methods of application are given in 3.6.2 through 3.6.5. 


\subsubsection{Thickness and Continuity}

3.6.1.1 Thickness of liquid films and use of thickness gauges. Liquid films shall be applied over surfaces to produce a new film lamination of the required dry uniform thickness. Exercise care to insure that all laps blend to produce a uniform appearance. Each application of coating shall be applied at the coverage rate (square feet per gallon) necessary to obtain the dry film thickness as specified therein. A film thickness gauge may be used by the contractor as a guide to indicate whether the coverage rate of paint is sufficient to produce the specified dry film thickness. However, the specified dry film thickness must be obtained. Before use, all wet and dry film thickness gauges must be approved for adequacy and calibration by the contracting officer's representative. Adulteration of the pain to obtain wet or specified dry film thickness readings will not be permitted.

NOTE: Show paint coverage rates or dry film thicknesses under the specific material paragraph or in the Work Schedule.

NOTE: The dry film thickness of the primer shall be greater than the nominal anchor pattern depth of the surface as measured by surface profile gage.

3.6.1.2 In the event the required thickness is not achieved as specified, additional paint shall be applied until the required thickness is obtained.

3.6.1.3 Dry or wet film thickness will be gaged or approximated by the government utilizing some or all of the test equipment listed in paragraph 1.12 .6 . The dry film thickness may be calculated by multiplying the wet film thickness by the percentage of non-volatile content of the inaterial being applied.

3.6.1.3.1 On rough or extremely irregular surfaces where consistent film thickness readings cannot be made, estimate the wet film thickness from a ineasured spread rate, square feet per gallon, and calculate the dry film thickness by multiplying the wet film thickness by the percentage nonvolatile content of the material applied.

3.6.1.3.2 Holiday detectors and magnifying lenses will be used to examine defects such as holidays (pits) and other surface blemishes in the film. Magnifying lenses of 20 power will be used to inspect for mildew or other foreign substances in the dry film. A draw-down applicator for comparison may be used to measure variations in color, gloss, and opacity of the film. Viscometers may be used to check paint consistency in the applicator's container for compliance with product specification. Limited use of thinner under specific conditions may be approved by the Contracting officer's representative to overcome a peculiar job condition or to prepare the paint for conventional air spray painting. Approved use of thinner will not be in excess of one pint of thinner per gallon of paint unless the particular type of paint (such as vinyls, SSPC-Paint 
Specification Nos. 8 or 9) requires more thinner for proper application. The use of thinner for any reason will not relieve the contractor from obtaining specified coating coverage and film thickness. Primer coats may be tinted as designated by the Contracting officer's representative.

3.6.2 Brushing. Brush application of paint shall be in accordance with the following:

3.6.2.1 Brushes shall be of a style and quality that will enable proper application of paint (round or oval brushes are generally considered most suitable for rivets, bolts, irregular surfaces, and rough or pitted steel. Wide, flat, brushes are suitable for large flat areas, but they should not have a width over five inches).

3.6.2.2 The brushing shall be done so that a smooth application as nearly uniform in thickness as possible is obtained.

3.6.2.3 Paint shall be worked into all crevices and corners.

3.6.2.4 There shall be a minimum of brush marks left in the applied paint.

3.6.2.5 (When applicable) It may be specified that paint be sprayed onto the metal followed by immediate and thorough brushing.

3.6.2.6 Surfaces not accessible to brushes shall be painted by spray daubers, or sheepskins.

3.6.3 Spraying. All spray application of paint whether air spray, airless, or hot spray, shall be in accordance with the following:

3.6.3.1 The equipment used shall be suitable for the intended purpose shall be capable of properly atomizing the paint to be applied, and shall be equipped with suitable pressure regulators and gauges. The equipment shall be kept in such condition as to permit proper paint application.

3.6.3.2 Paint ingredients shall be kept properly mixed in the spray pots or containers during paint application either by continuous mechanical agitation or by intermittent agitation as frequently as necessary.

3.6.3.3 Spray equipment shall be kept sufficiently clean so that dirt, dried paint, and other foreign materials are not deposited in the paint film. Any solvents left in the eqipment shall be completely removed before applying paint to the surface being painted.

3.6.3.4 Paint shall be applied in a unfform layer, with overlapping at the edge of the spray pattern. The spray pattern shall be adjusted so that the paint is deposited uniformly. During application, the gun shall be held perpendicular to the surface and at a distance which will insure that a wet layer of paint is deposited on the surface. 
3.6.3.5 Blind sides of all rivets, bolts, and all other areas inaccessible to the spray gun shall be painted by brush; if not accessible by brush, daubers or sheepskins shall be used. Brushes shall be used to work paint into cracks, crevices, and blind spots which cannot be painted by spray.

3.6.3.6 Particular care shall be observed with respect to type of thinner, amount of thinner, paint temperatures, and operating techniques in order to avoid deposition of paint which is too viscous, too dry, or too thin when it reaches the receiving surfaces.

3.6.3.7 Special provisions pertaining to airless spray are given in 3.6.4. 3.6.4 Airless Spray. Airless or high pressure spray application of paint shall be in accordance with all of the provisions of 3.6 .3 , and in addition shall comply with the following:

3.6.4.1 Fluid tips shall be of orifice size and fan angle, and the fluid control gun of construction, as recommended by the manufacturer of the material being sprayed and the equipment being used.

3.6.4.2 The regulated pressure to the paint pump shall be adjusted so that the paint pressure to the gun is proper for optimum spraying effectiveness. This pressure shall be sufficiently high to atomize the paint. Pressures considerably higher than those necessary to properly atomize the paint shall not be used.

3.6.4.3 Spraying equipment shall utilize filters in the high pressure line so that dirt, dry paint, and other foreign materials are not deposited in the paint film. Spray equipment shall be kept sufficiently clean to avoid excessive build-up of these materials in the filter. Enough paint should be pumped through the system so that any solvents left in the equipment shall be completely removed before applying paint to the surface being painted.

3.6.4.4 Airless paint spray equipment shall always be provided with an electric ground wire in the high pressure line between the gun and the pumping equipment. Further, the pumping equipment shall be suitably grounded to avoid the build-up of any electrostatic charge on the gun, as may occur when certain types of materials are sprayed.

3.6.5 Rollers. Roller application is permissible under certain circumstances, as described in 3.6. Paint rollers shall be of the following style and quality to insure application, continuity, and thickness as required in 3.6.1. Paint applied by roller shall be rolled in two directions, the second pass at right angles to the first.

$\begin{array}{lll} & \text { Surface } & \text { Kough }\end{array}$

NOTE: Use AFM 85-3, chapter 4, and specify for each type paint specified and each type of surface, the proper roller material and nap length. 


\subsubsection{Ferrous Surfaces:}

NOTE: The following provisions are to be used for routine painting, where no peculiar problems have been noted. For corrosive atmosphere or application methods for specific coating systems use specifications in Steel Structures Painting Council Manual, volume 2. Applicable sections of these specifications should be quoted in the contract specification to provide inspectors and other contract officials with ready access to the provisions of the contract.

3.6.6.1 Particular care shall be taken to prevent the contamination of cleaned surfaces with salt, acids, alkali, or other corrosive chemicals before the primer is applied and between applications of the remaining coats of paint. Such contaminants shall be removed from the surface. The pretreatment of prime coat shall be applied immediately after the surface has been cleaned. Succeeding coats shall be applied before contamination of the under surface occurs.

3.6.6.2 Cleaning and painting shall be so programmed that detrimental amounts of dust or other contaminants do not fall on wet, newly painted surfaces. Surfaces not intended to be painted shall be suitably protected from the effects of cleaning and painting operations.

3.6.6.3 On structures that are known to have been originally pretreated with basic zinc chromate wash primer pretreatment, the cleaned areas shall, unless otherwise specified, be similarly pretreated before applying the primer paint.

3.6.6.4 First application of other than vinyl-type wash coatings shall be applied by brush, except where the item has been shop primed or field primed. The first application may be applied by brush, roller, or spray. Subsequent applications may be applied by brush, roller, or spray. Vinyl-type wash coating may be applied by brush, spray, or swab.

3.6.6.5 Vinyl-type wash coating shall be applied at a rate of maximum practical wet film thickness. Care shall be exercised in spray application to avoid the deposition of dry particles on the surface. A wet spray shall be maintained at all times. Surfaces treated with the wash coat shall be permitted to dry for not less than one hour and shall be coated as soon thereafter as practicable, but within 48 hours after application and before any deterioration or accumulation of dust or dirt.

3.6.6.6 Steel stacks and other ferrous surfaces subject to elevated temperatures. The types of paints used for these surfaces are indicated in the Work Schedule herein. Paints shall not be applied when surface temperatures are above $140^{\circ} \mathrm{F}$.

3.6.6.7 Coating systems for interior ferrous surfaces of petroleum storage tanks. The entire interior of (all new, existing) steel tanks for 
storage of petroleum products shall be coated in accordance with the following requirements:

3.6.6.7.1 The coating material shall be an epoxy coating system conforming to specification MIL-C-4556. The coating system shall consist of a primer coat and two or more finish coats as required to achieve a total dry film thickness of not less than 7 mils.

3.6.6.7.2 The primer coat shall be applied as soon as possible after the blast cleaning. In no case will the time interval exceed 8 hours. If any visible rusting does occur after blasting, regardless of the time interval, the surface shall be reblasted prior to applying the primer coat. The application of the lining shall not be done when the steel surface temperature is less than $2^{\circ} \mathrm{F}$ above the dew point temperature of the surrounding air. This condition will most likely occur in underground tanks. For such cases heated air shall be circulated through the tank as required to maintain this $2^{\circ} \mathrm{F}$ temperature differential and thereby prevent condensation of moisture on the tank surface.

3.6.6.7.3 Zinc rich primers shall be applied at a coating thickness according to the manufacturer's recommendations. Application of these primers shall strictly follow the manufacturer's recommendations for suitable film thickness; for too thick films as well as too thin films may both lead to premature filures. Follow manufacturer's directions for proper curing time of the zinc rich primer before application of any topcoat. Follow manufacturer's recommendations for application of a mist coat directly over the cured zinc rich primer.

3.6.6.7.4 The coating system shall be applied by experienced applicators in strict conformance with the manufacturer's recommendations. A manufacturer's representative shall be present during the initial phase of the application. Curing instructions and safety precautions shall be rigidly followed.

NOTE: Shop-fabricated tanks shall be interior coated by the tank manufacturer prior to delivery. Field fabricated tanks shall be coated in the field after completion of the tank. Approval to interior coat existing tanks must be obtained from HQ USAF/LEEES on an individual basis as required by AFM 85-16. Also reference should be made to existing tanks, which will be written into these specifications. These tanks, when authorized, shall be interior coated as described above for new tanks except for floating roof tanks with metallic sealing rings. The interior coating of tanks with metal to metal roof seals requires special consideration, and specifications for lining this type of tank shall be obtained from HQ USAF/LEEES.

\subsubsection{Miscellaneous Applications and Special Requirements}


3.6.7.1 Vinyl Paint Systems. Vinyl and vinyl-alkyd paints are not compatible with conventional paints and shall not be used on conventionally primed surfaces or surfaces shop coated with ferrous metal primer or a manufacturers standard rust inhibiting primer.

3.6.7.1.1 Vinyl-resin paint VR-3:

Application Application Method Minimum Drying Time

Brush

Spray

Spray

Spray
12 hours

12 hours

12 hours if a fourth lamination is to be applied or at least 10 days before placing in service if only 3 laminations are used.

At least 10 days before placing in service.

The paint shall be applied in three or four applications. The overall total dry thickness of the three application system will be from five to seven mils. The overall total dry film thickness of the four application system will be from six to eight mils.

NOTE: As a guide, 225 square feet per gallon per application usually gives a dry film thickness of about $1.7 \mathrm{mils}$, but is not required to do so by the materials specifications. Variables such as surface roughness, application technique, amount of overspray, etc., affect the final spreading rates obtained. Use the four application system for severe to the most severe environments. Use the three application system for moderately severe corrosive conditions.

\subsection{MISCELLANEOUS:}

3.7.1 Lettering shall be provided as scheduled on the drawings, shall be of the (block, Gothic) type, and shall be (black enamel, water-type decalcomanias finished with a protective coating of spar varnish). Letcers shall conform to approved samples and shall be executed by craftsmen skilled in this type of work.

NUTE: Review drawings to insure specification and drawings are in accord.

3.7.2 Contractor will repaint number, symbols, arrows, etc., after surfaces on which these items exist, have been finish-painted. 
3.7.3 Installation of Removed Items. Following completion of painting of each space, removed items, listed under section 2, Cleaning, Preparation, and Pretreatment of Surfaces shall be reinstalled by workmen skilled in the trade involved.

\subsubsection{Obstructions to Flying:}

NOTE: When the project is on or adjacent to a civil or military airfield, consult the regulations of the cognizant authority and specify any structure found to be an obstruction to flying, by name. Include obstruction painting of such structures as towers and elevated tanks in the respective section.

shall be painted in the pattern prescribed by Federal Administration publication, Obstruction Marking and Lighting. International orange and white enamel shall be used for obstruction markings.

3.8 CLEANING. Cloths and cotton waste that might constitute a fire hazard shall be placed in closed metal containers or destroyed at the end of each day. Upon completion of the work, staging, scaffolding, and containers shall be removed from the site or destroyed in an approved manner. Paint spots, oil, or stains upon adjacent surfaces shall be removed and the entire job left clean and acceptable.

\subsection{ORDER OF WORK.}

3.9.1 General. The contractor will present to the Contracting officer a progress schedule listing the dates he proposes to begin work in each area as shown on the contract drawings or otherwise indicated in contract documents. The Contractor will limit his activities to one area at a time and will complete all work items therein before commencing operations in a succeeding area.

3.9.2 Deviation from Order of Work. If the Contractor's work has progressed to the point, in a given area, where the work remaining can be accomplished by a reduced labor force, the Contractor may request approval in writing from the Contracting officer to begin work in a succeeding area. The Contractor will not begin work in a succeeding area until he has received written approval from the Contracting officer. 


\section{SECTION 4}

\section{PAINTING SCHEDULE}

NOTE: Incorporate the PAINTING SCHEDULE into the contract specifications. Delete surfaces not occurring in the project or not required to be painted from the PAINTING SCHEDULE. If specific finish coatings are required for specific areas show such requirements in a schedule on the drawings, and coordinate the specifications with such schedule. Where applicable, list the specific items to receive a particular paint system under the appropriate heading in the SURFACE column of the PAINTING SCHEDULE. List surfaces requiring coating in the PAINTING SCHEDULE, and designate the surfare preparation, pretreatment, and coating specification for such surfaces.

4.1 PAINTING SCHEDULE. Except as specified under paragraph SURFACES NOT TO BE PAINTED, the surfaces listed in the PAINTING SCHEDULE shall receive the surface preparation, paints, and number and thickness of coats prescribed. (Piping shall not be painted until it has been tested and approved.) Explanatory information for use with the painting schedule 18 as follows:

4.1.1 Shop-Painted Items. Surfaces of fabricated and assembled items that are finish-painted by the manufacturer, or specified to be finish-painted under other sections of the specifications, are exempted from the follow ing schedule requirements for surface preparation and painting. Shopprimed items shall receive surface preparation and finish painting as required by this section.

4.1.2 Colors and Tints. Colors and tints shall match the respective color specimens selected by the contracting officer from Federal Standard 595 color. Undercoats shall vary slightly in color from the color of the next coat (when applicable).

4.1.3 Surface Preparation and Pretreatment. These comments are general in nature and indicate only the broad scope of work to be done. Surface preparation and pretreatment prior to painting shall be accomplished as required in detail by Section 2 of this specification.

\subsubsection{Color-Code Marking:}

NOTE: Piping will be color-coded in accordance with Military Standard 101 , Color Codes for Pipelines and Compressed Gas Cylinders, Military Standard 161, Identification Methods for Bulk Petroleum Products Systems including Hydrocarbon Missile Fuels, and Military Standard 172 color code for containers of liquid propellants.

Marking for piping systems shall be provided as specified in table 1. Paint shall be as specified for insulated and uninsulated piping. 
TABLE 1. CULOR CODE SCHEUULE

\begin{tabular}{|c|c|c|c|}
\hline & \multicolumn{2}{|c|}{ Color } & Location of \\
\hline Piping & Primary & Secondary & Identification \\
\hline
\end{tabular}

4.1 SUKFACES NOT TO BE PAINTED

NOTE: L1st surfaces such as concrete floors, structural concrete, permanent siding, and other surfaces which are not to recelve protective coatings.

NOTES ON PAINTING SCHEDULE:

a. Paint exterlor galvanized surfaces and exterior aluminum and aluminum alloy surfaces only when corrosion conditions are extreme.

b. Paint intertor galvanized surfaces only when the surfaces would present a poor appearance if left bare.

DRAFT PRINTING SCHEDULE*

\section{SURFACE}

Exterior ferrous surface subject to moderate to severe atmospheric exposure

\section{SURFACE PREPARATION}

Near white metal blast cleaning, S.S.P.C. SP 10

Near white metal blast cleanIng, SSPC - SP 10
Exterior ferrous ourfaces subject to high temperature exposures

IST COAT
V R - 3
$(v 1 n y 1)$
$(1.5$ m11)
MIL-P-23236
(Inorganic
z1nc, s111-
cate) Type
I, Class 3
$(3.5$ m11)

2ND COAT

3RD COAT

V R - 3

V R - 3

(1.5 m11)

(1.5 m11)

$V R-3$

(1.5 m11)

Commercial blast cleaning, SSPC SP 6

\begin{tabular}{|c|c|c|c|}
\hline & & $\begin{array}{l}\text { Mist coat of } \\
\text { (mod1f1ed } \\
\text { acryl1c) }\end{array}$ & $\begin{array}{l}\text { (Modlfied } \\
\text { acryl1c) }\end{array}$ \\
\hline $\begin{array}{l}\text { Commerclal blast } \\
\text { leanlng, SSPC - } \\
\text { P }\end{array}$ & $\begin{array}{l}\text { MIL-P-23377 } \\
\text { (Epoxy polya- } \\
\text { mide) }\end{array}$ & $\begin{array}{l}\text { MIL-P-23236 } \\
\text { (Urethane) } \\
\text { Type I, } \\
\text { Class } 4\end{array}$ & \\
\hline
\end{tabular}

Commercial blast

SSPC - SP 6

$\begin{array}{cc}V R-3 & V R-3 \\ (1.5 \mathrm{~m} 11) & (1.5 \mathrm{ml1})\end{array}$

$(1.5 \mathrm{m11}) \quad(1.5 \mathrm{m11})$

Class 4

\author{
TT-P-28 (to \\ $\left.1200^{\circ} \mathrm{F}\right)(\mathrm{Al} \mathrm{u}$ \\ minum) MIL-P- \\ 14104 (to $1400^{\circ}$ \\ F) Silicon \\ frit
}

\section{Exterior galvanized steel surfaces subject to moderate to severe atmospher $1 c$ exposure}

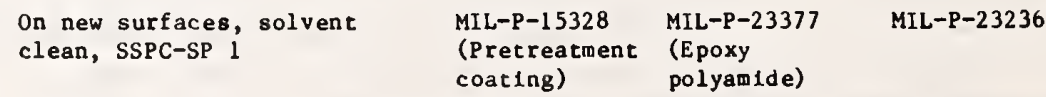

\author{
MIL-P-23236 \\ (Modified \\ acryl1c)
}

$\begin{array}{lllll}\text { Intertor ferrous } & \begin{array}{l}\text { Near white metal blast } \\ \text { cleaning } \\ \text { SSPC-SP } 10\end{array} & \text { VR } R-3 \quad \text { V R }-3 \quad \text { MIL-P-24441 }\end{array}$

$\begin{array}{ll}\text { Interior ferrous } & \text { Near white metal blast } \\ \text { fuel tanks } & \text { sleaning } \\ & \text { SSPC-SP } 10\end{array}$

\footnotetext{
The complete coating system, e.g. primer, top coat, will be furnished by one manufaturer. The system must be subnitted as a family. When the bid is submitted, the bidder must indicate the mantfacturing source. The paint films to be applied at manufacturer's recommended dry film thickness. Do not permit dry film thickness
} application more than $1-m i l$ greater than manufacturer's recommendation. 


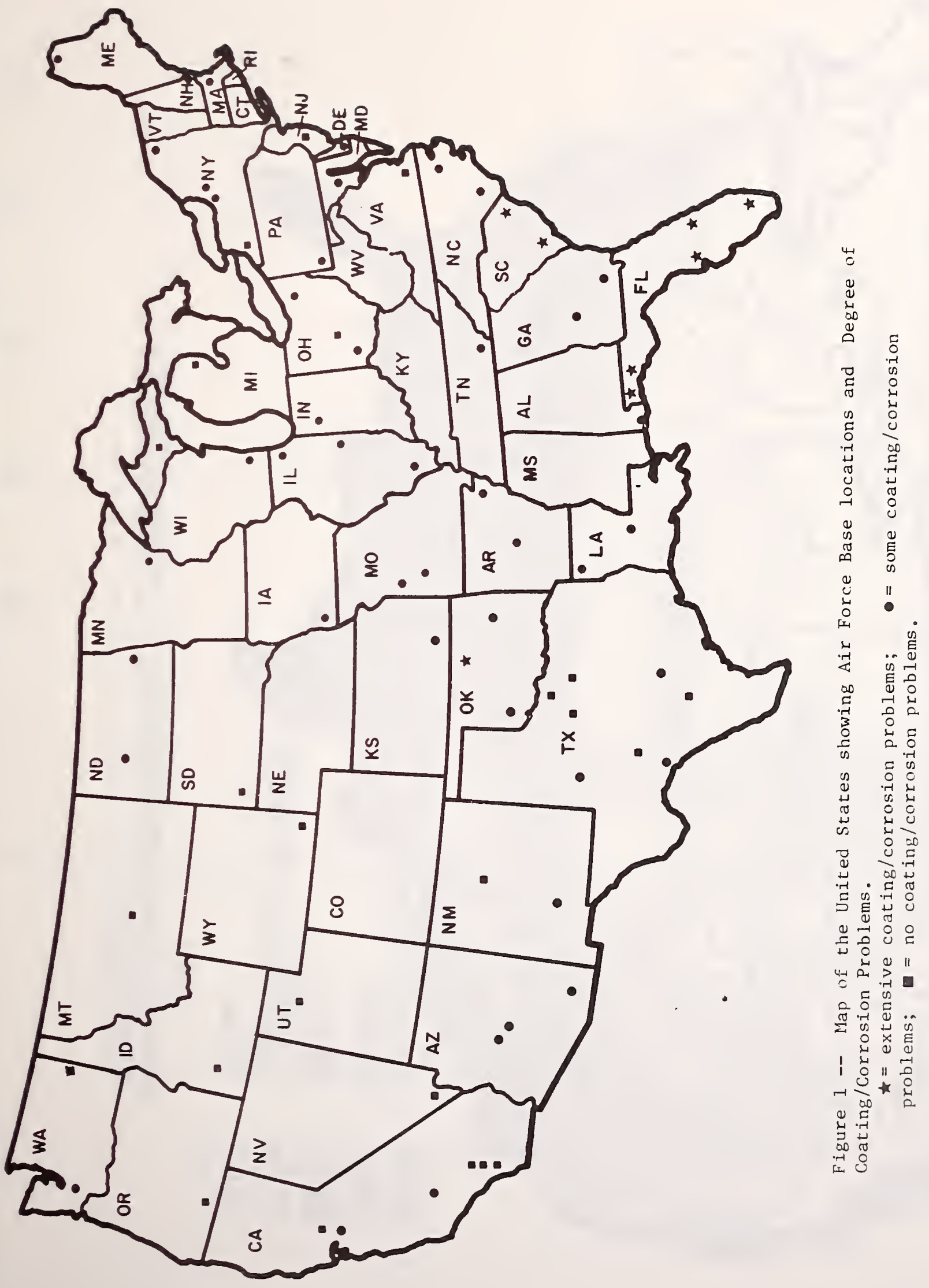




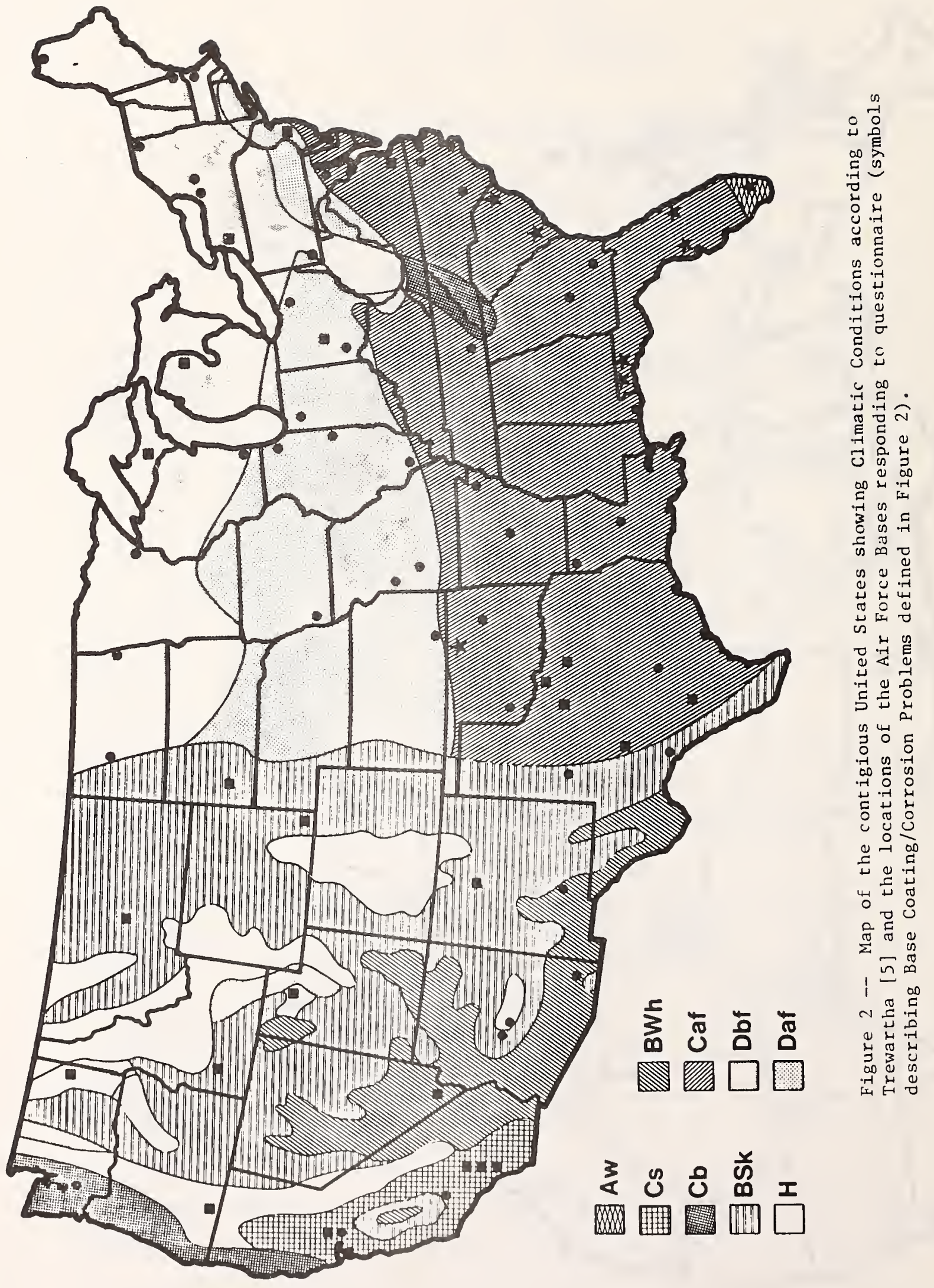




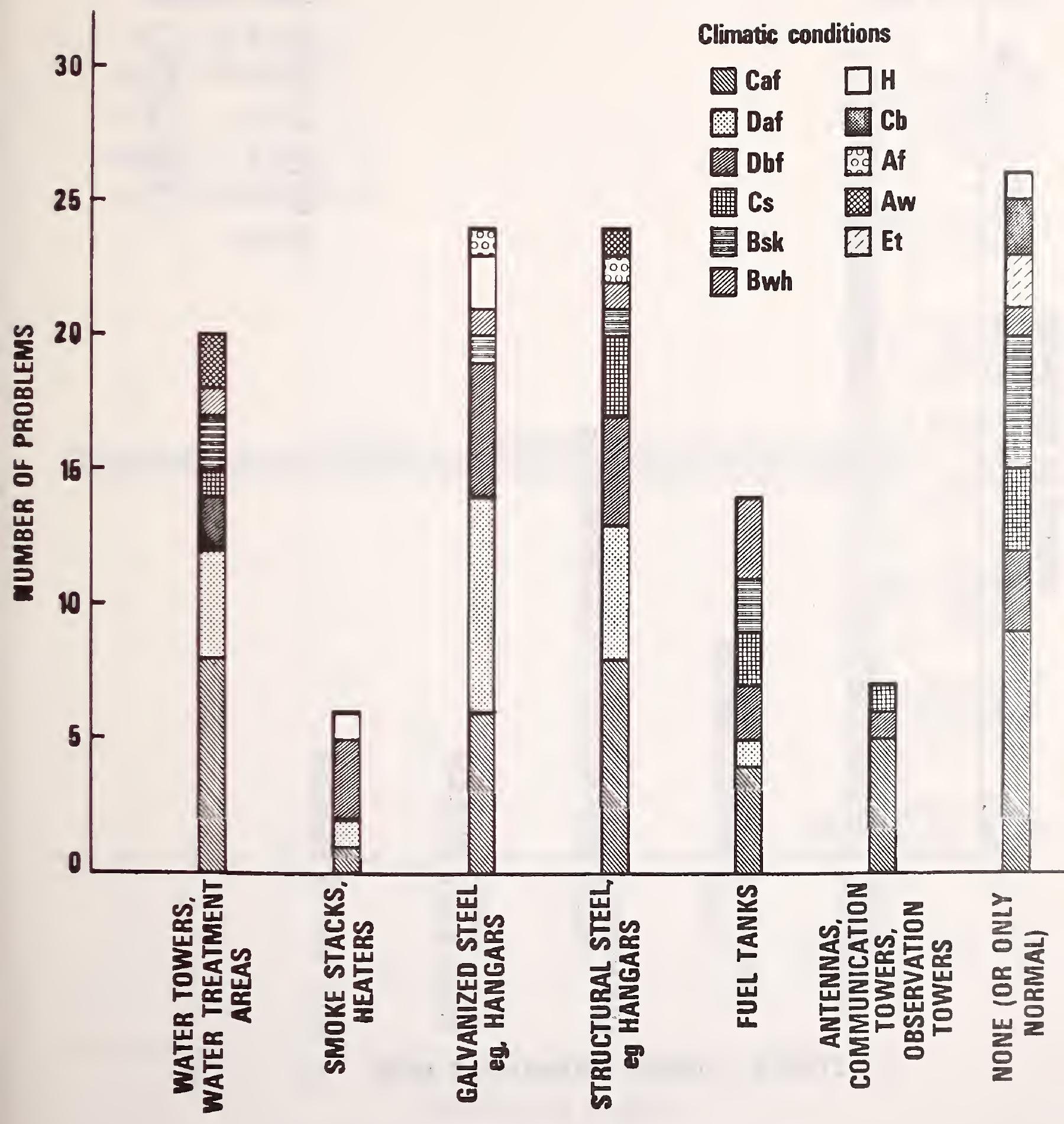

Figure 3 -- Coating/Corrosion Problems versus Type of Steel Structure. 


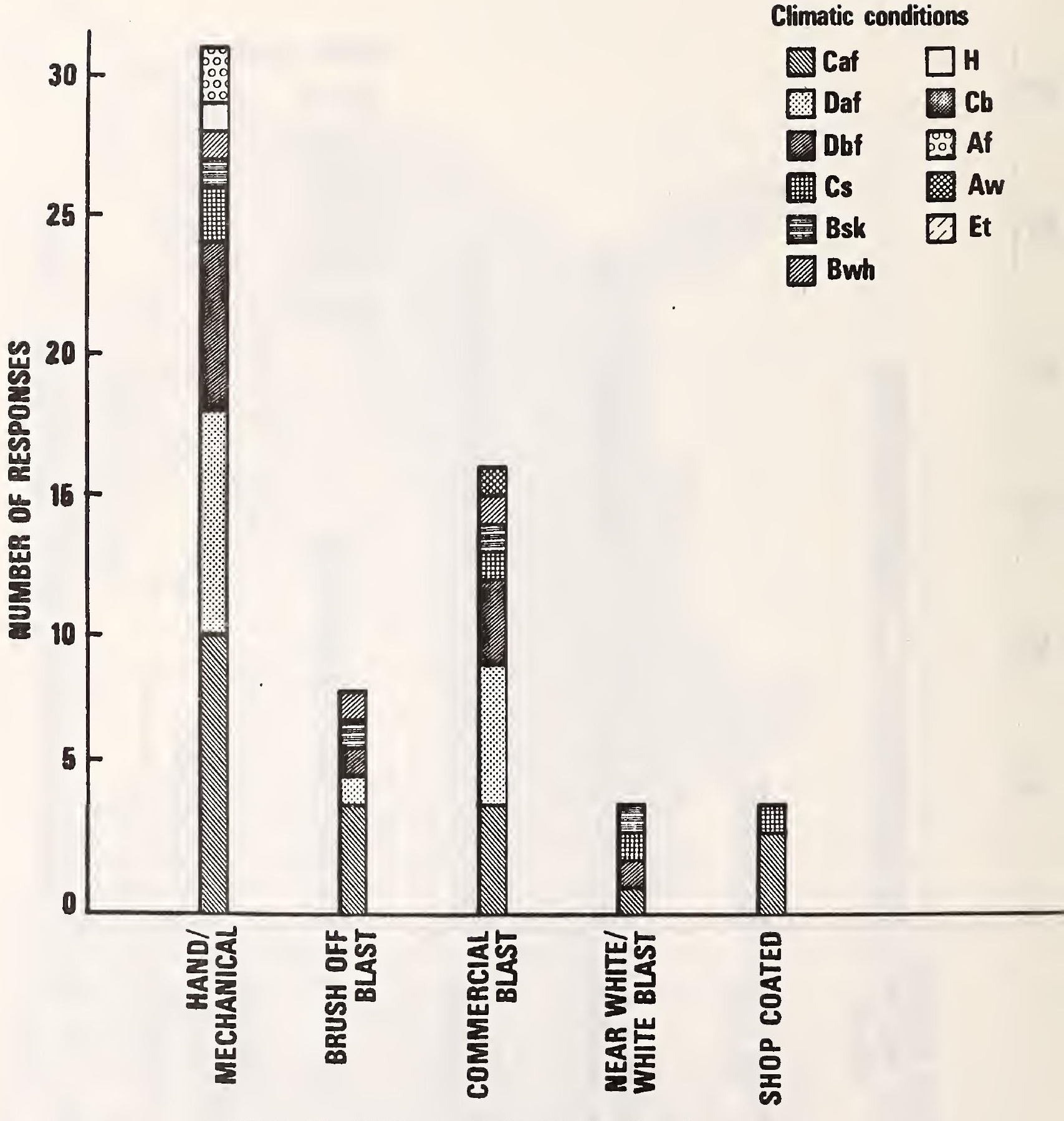

TYPE OF SURFACE PREPARATION USED

Figure 4 -- Coating/Corrosion Problems versus

Type of Surface Preparation Used Prior to Painting. 


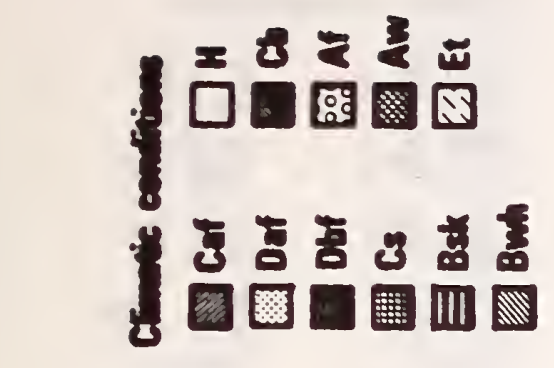

NMONXN

WกNIWกา

INOJITIS

- JN

N캣S

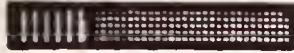

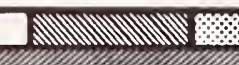

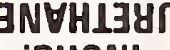

'פषONI

HכIY JNIZ

1४0J d01

0גหาช

yawitd

อมหาษ

0גหา

3NODIIIS

yjWIyd

0ג>77

1800 d01

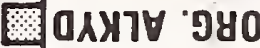

HगIY JNIZ

$1 \forall 03$ d01

7ANIA "פYONI

HJI8 JNIZ

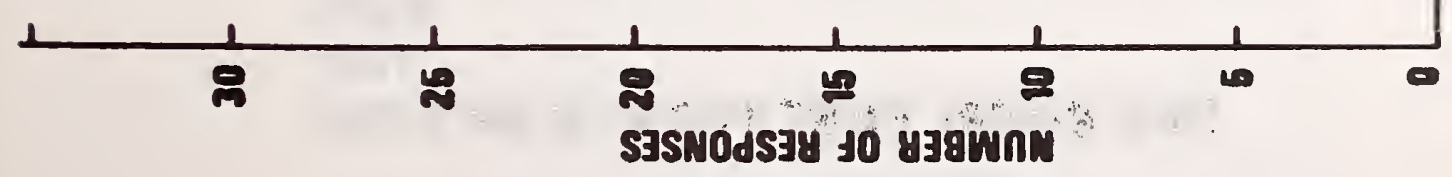

TANIA

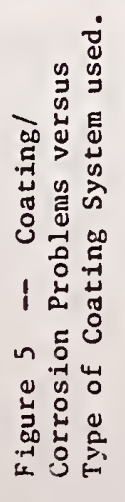


Climatic conditions
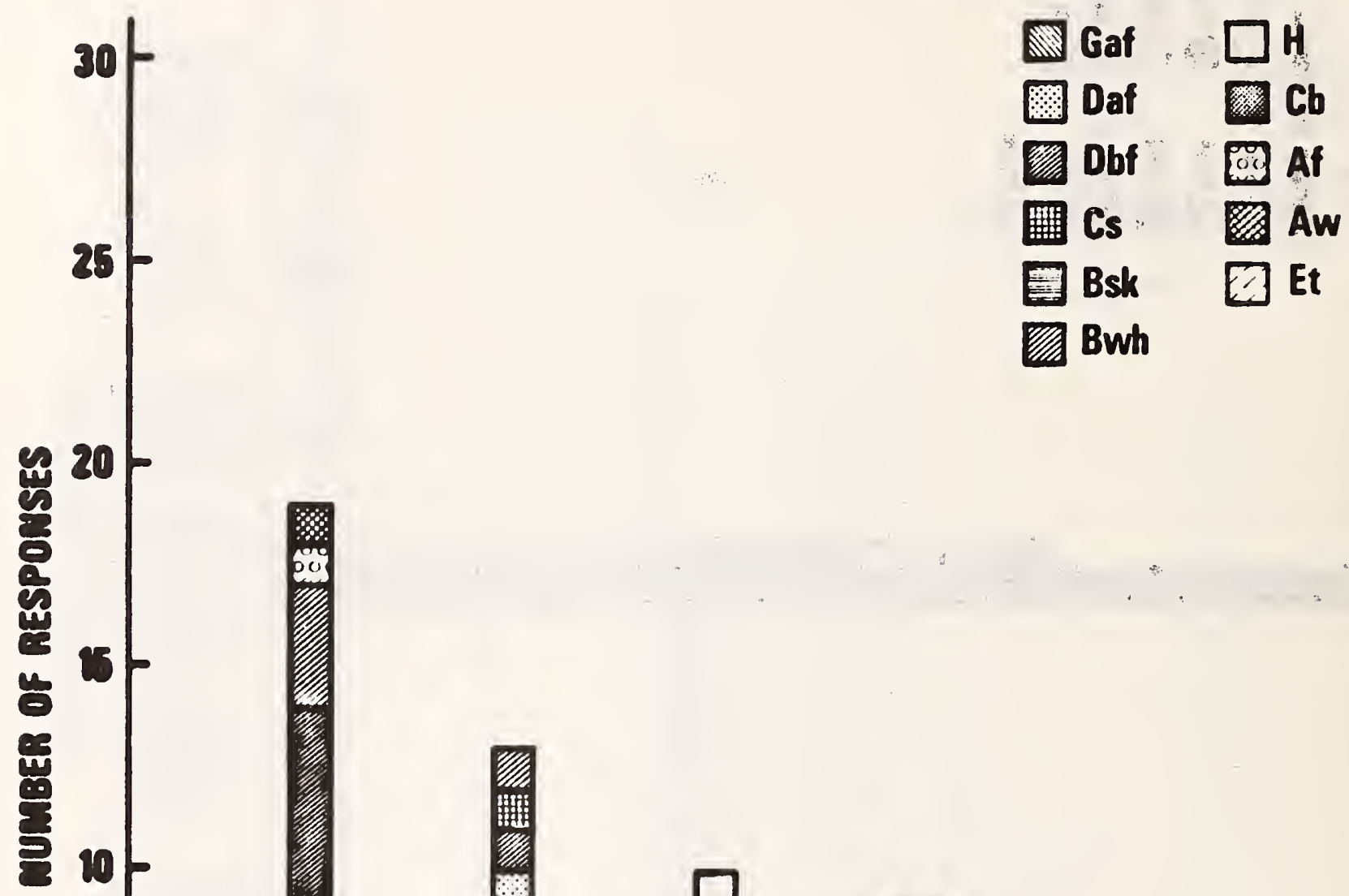

Figure h -- Contingfourrosion l'roblems versus time Before Problem Appearud. 


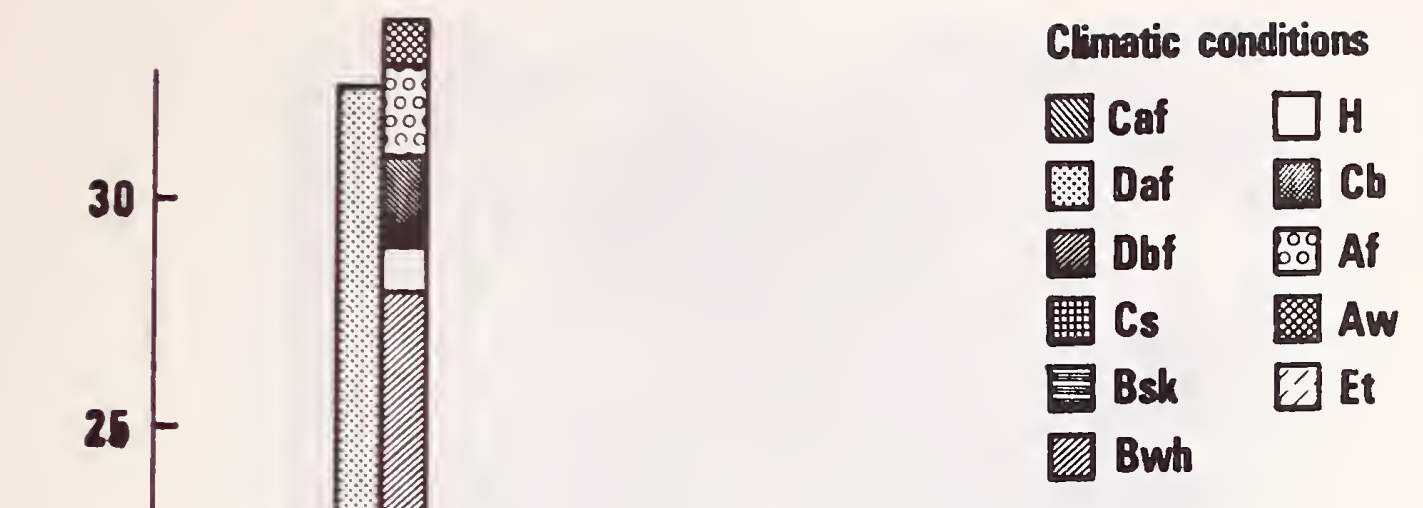

Figure 7 -- Frequency of Air Force Base Painting. 


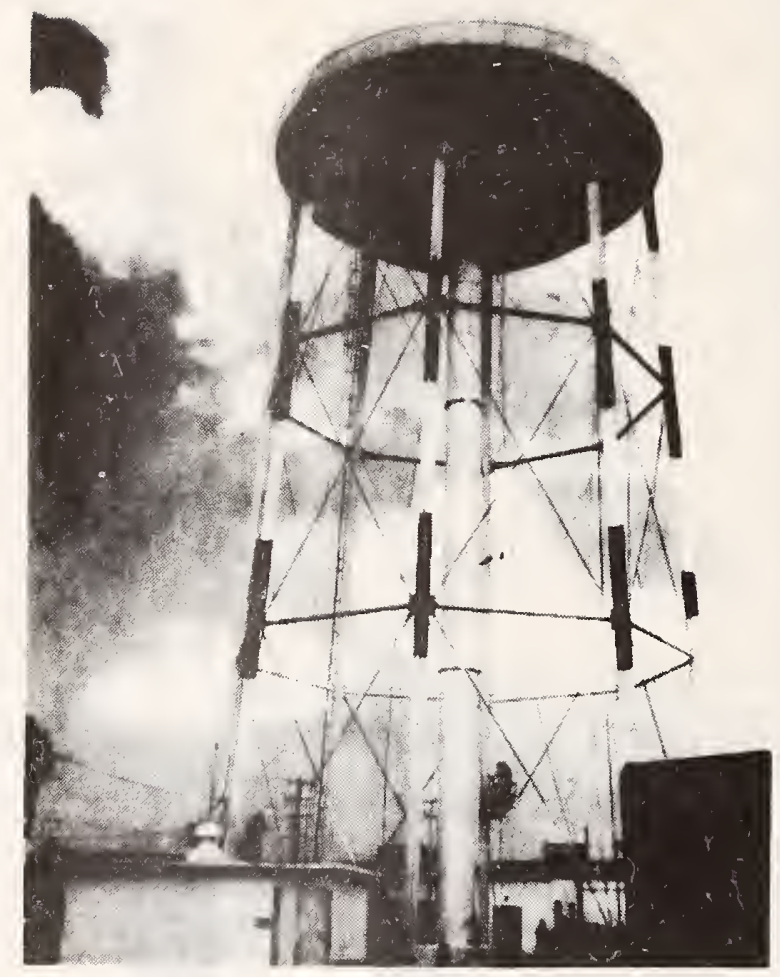

Figure 8 -- Water Tower, Patrick AFB, Overall View of Tower Undergoing Repair.

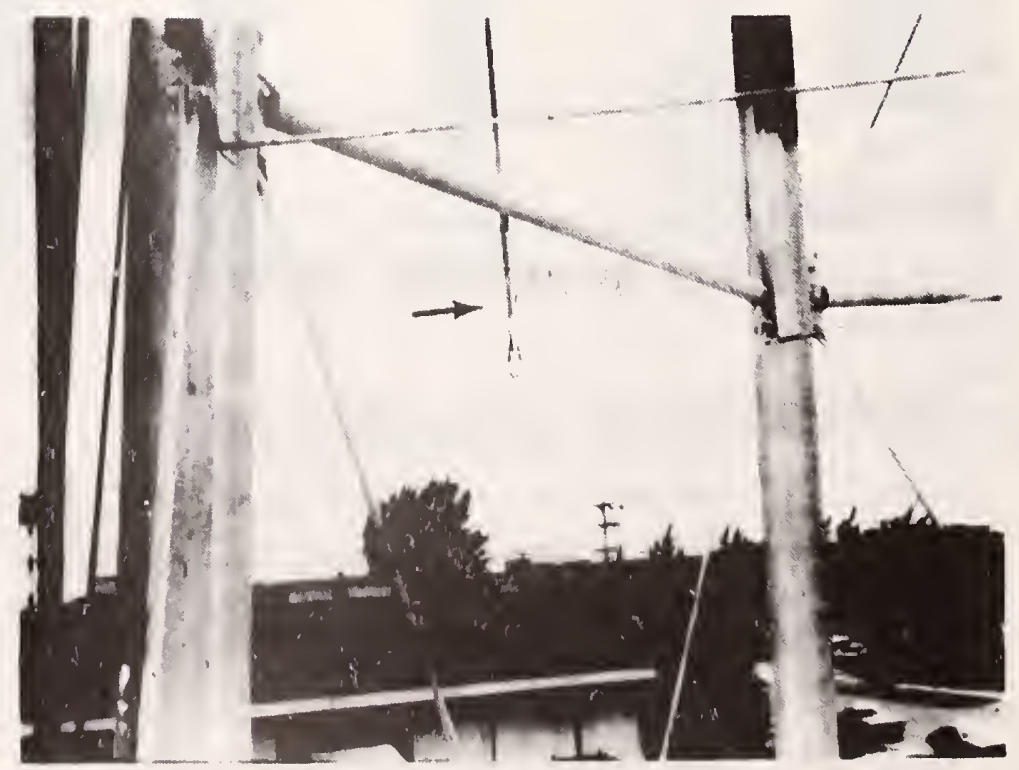

Figure 9 -- Water Tower, Patrick AFB, Loose Support. 


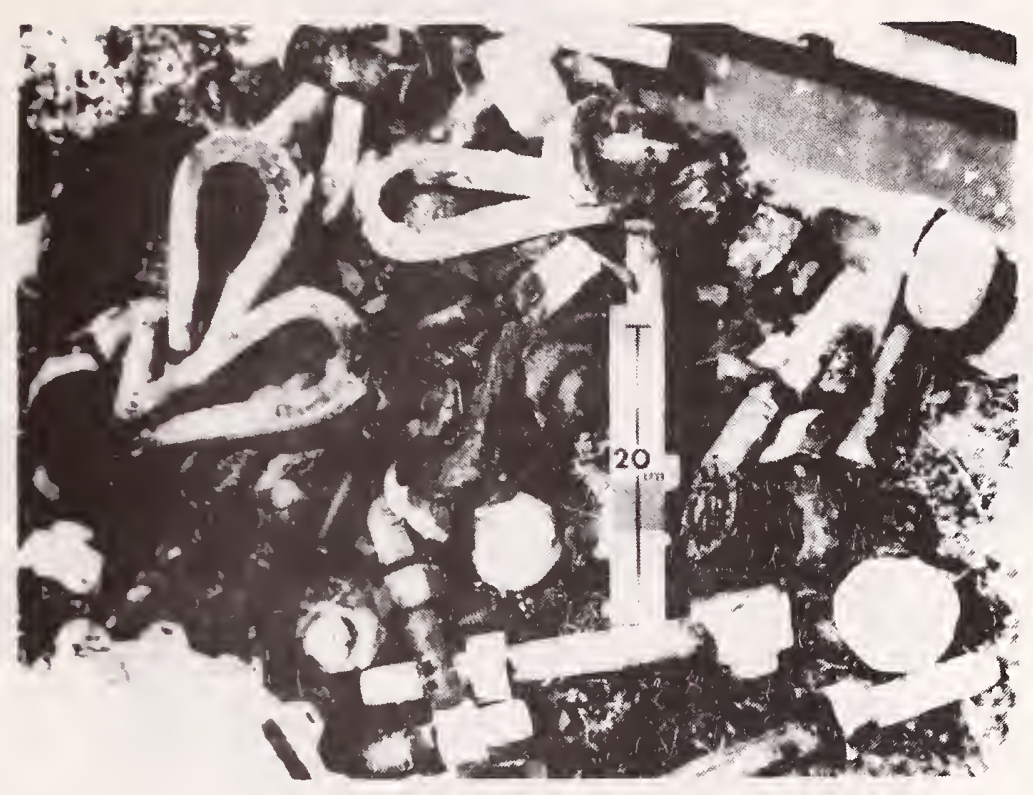

Figure 10 -- Water Tower, Patrick AFB, Corroded Bolts Removed During Repair of Tower.

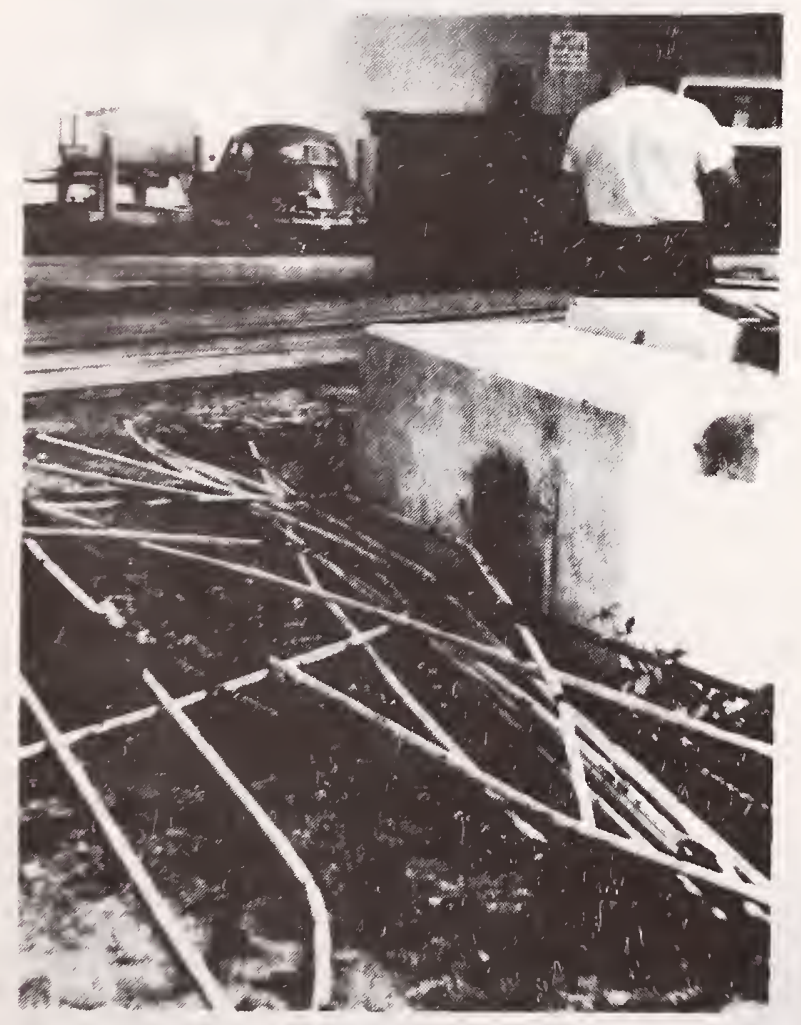

Figure 11 -- Water Tower, Patrick AFB, Corroded Support Rods Removed Juring Repair of Tower. 


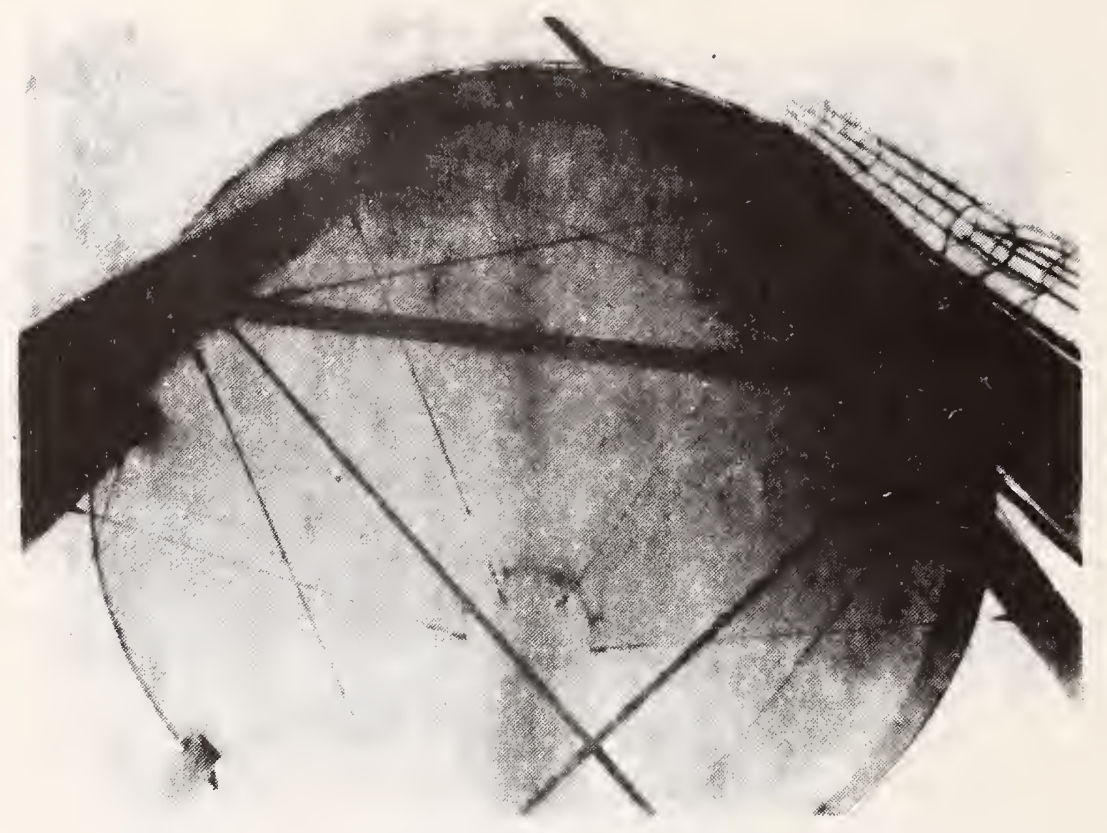

Figure 12 -- Water Tower, Patrick AFB, Recently Painted Tower。

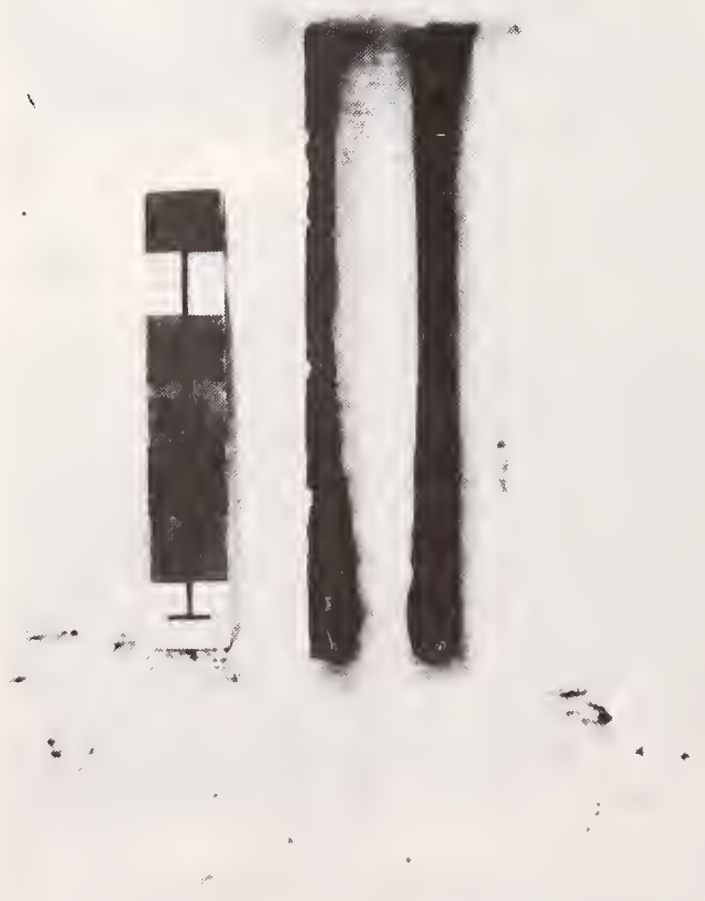

Figure 13 -- Water Tower, Patrick AFB, Base of Recently Painted Tower. 


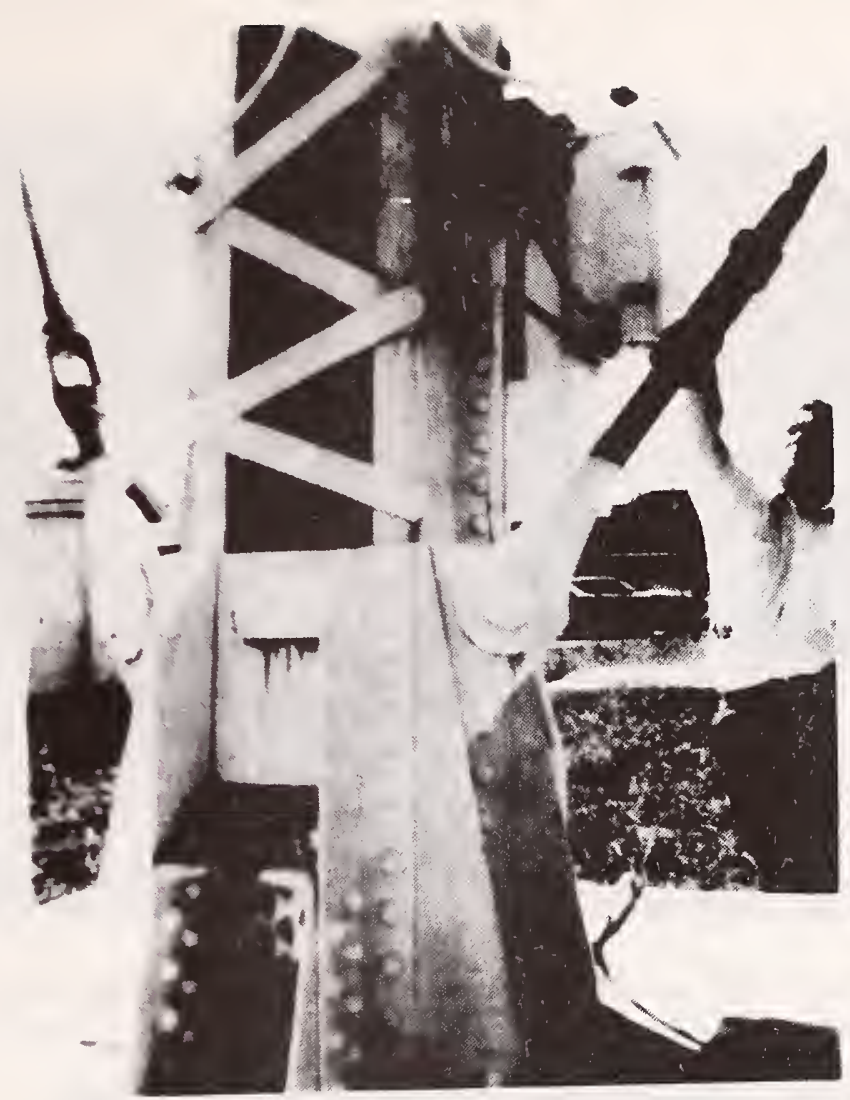

Figure 14 -- Water Tower, Tyndall AFB.
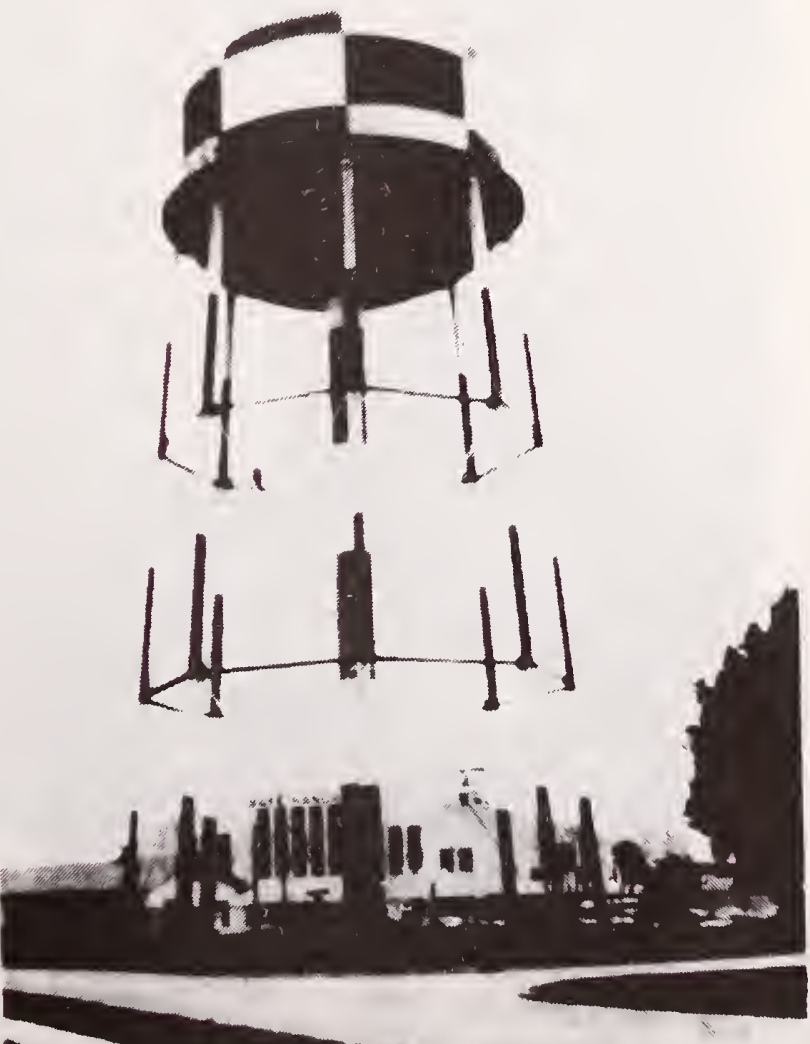

Figure 15 -- Water Tower, MacDill AFB, Zinc Rich Inorganic Primer with Vinyl Topcoat. 


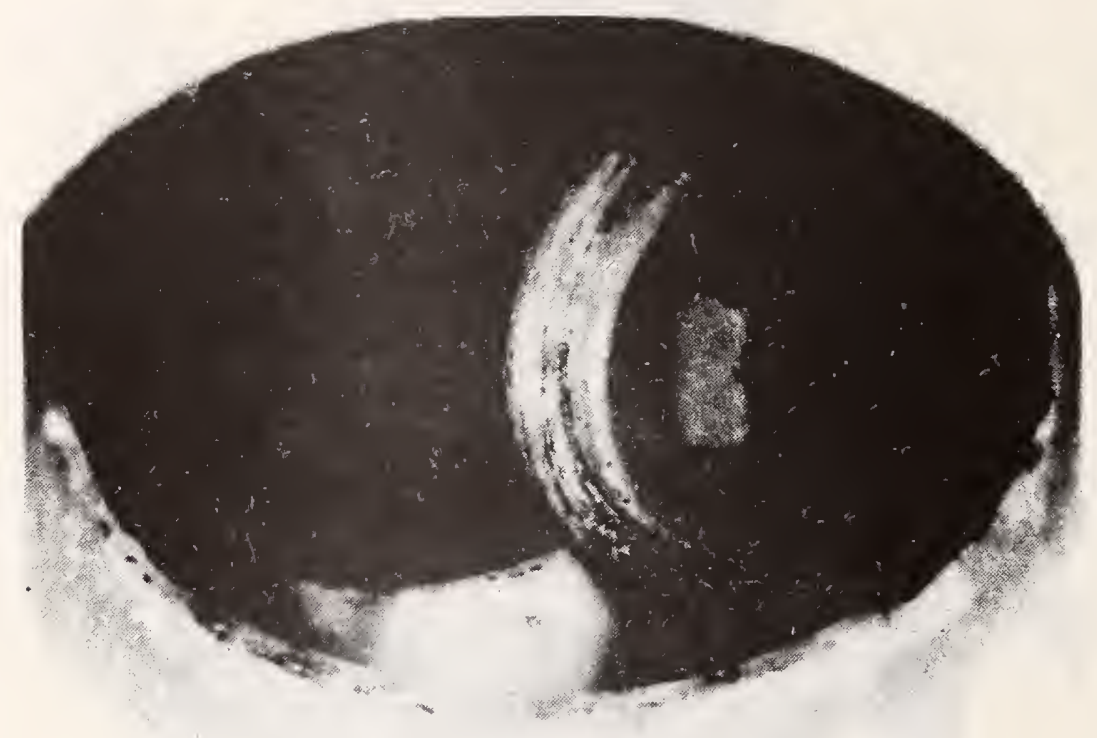

Figure 16 -- Water Tower, Eglin AFB, Interior View of Vinyl Coated Riser.

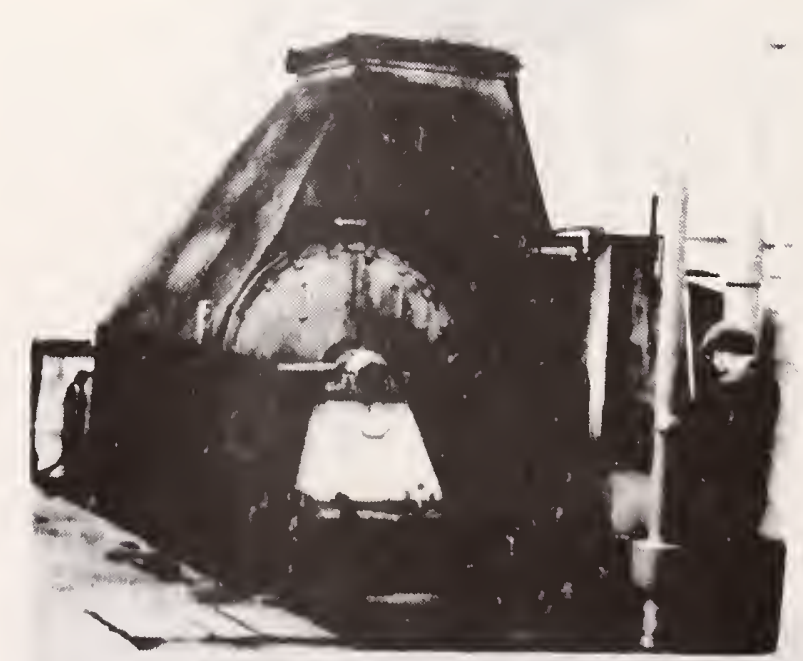

Figure 17 -- Heating Stack, Dover AFB. 


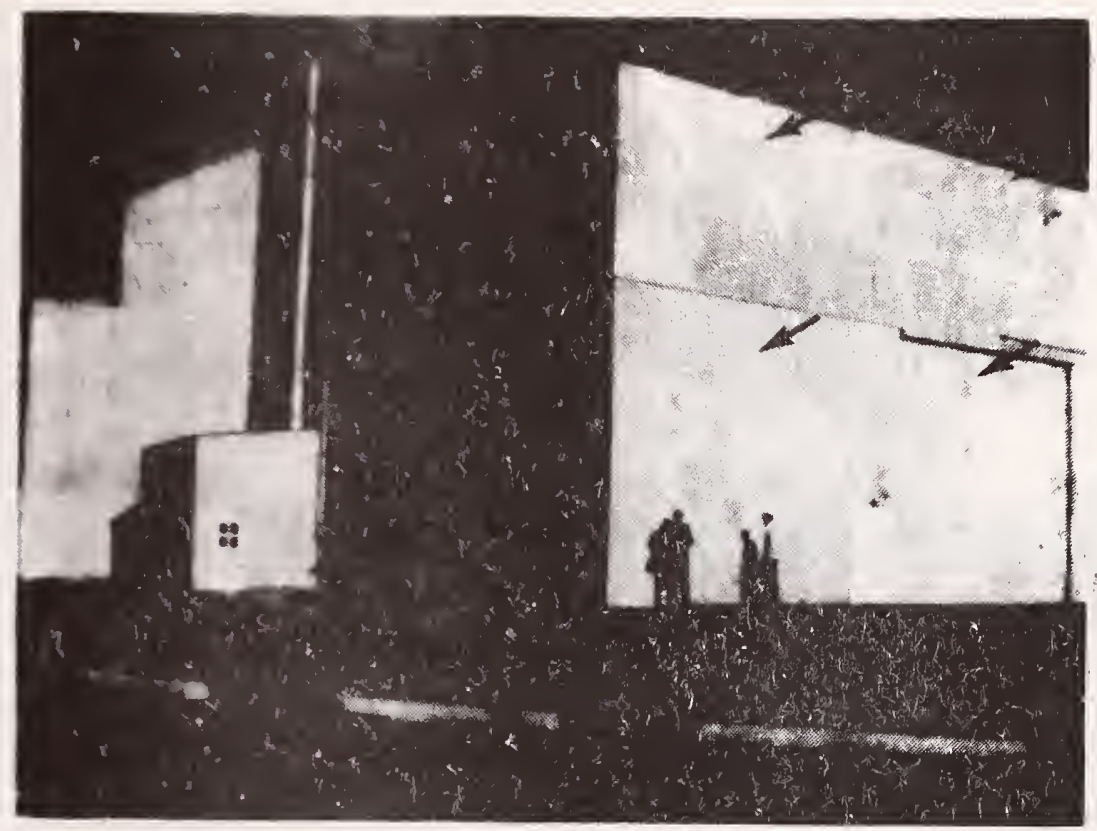

Figure 18 -- Hanger, Dover AFB, Coating Failure on Galvanized Steel Cladding (indicated by arrows).

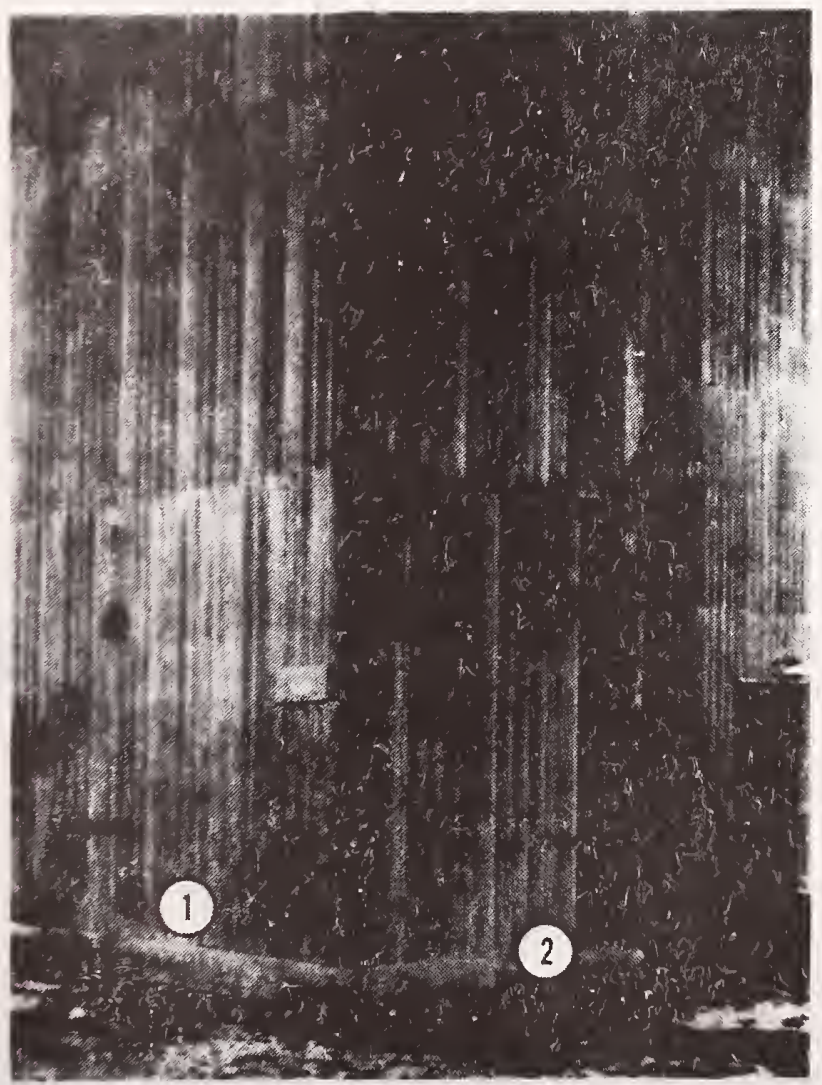

Figure 19 -- Nose Dock, Patrick AFB, (1) indicates side exposed to ocean with corroded galvanized steel fastners, (2) side of building facing inland, with no corrosion of fastners. 

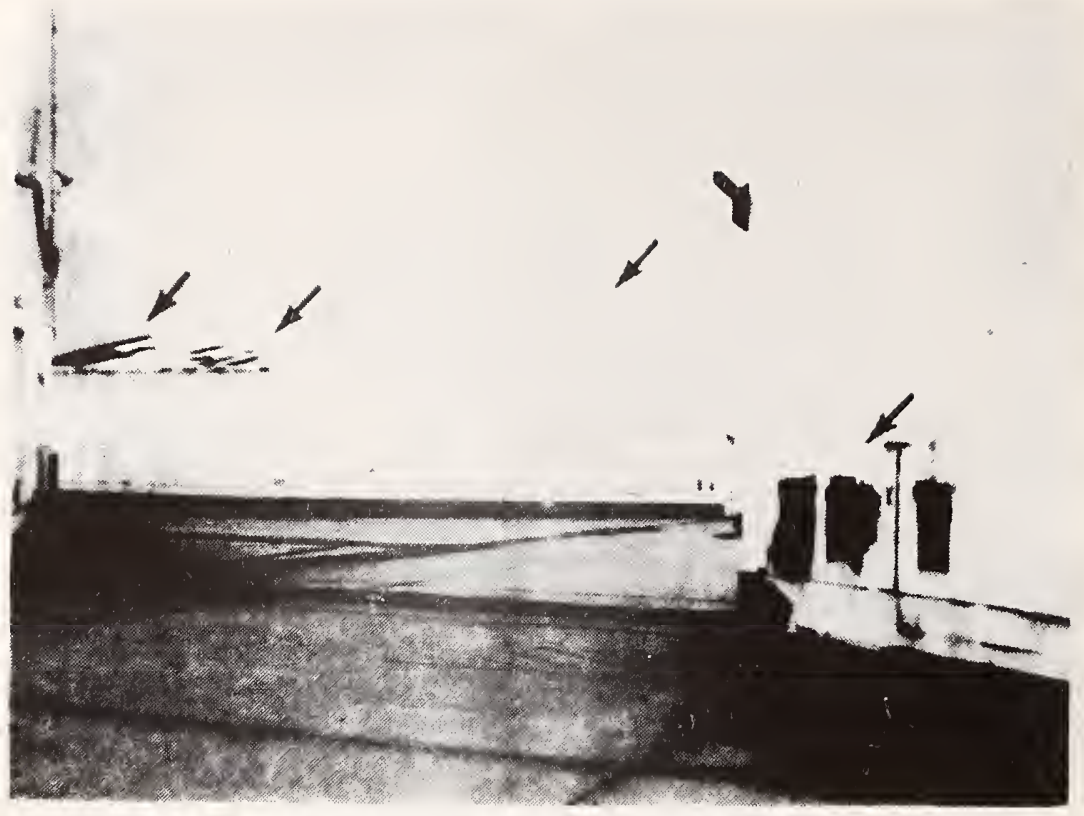

Figure 20 -- Nose Dock, MacDill AFB, Delamination of Elastomeric Coating (indicated by arrows).

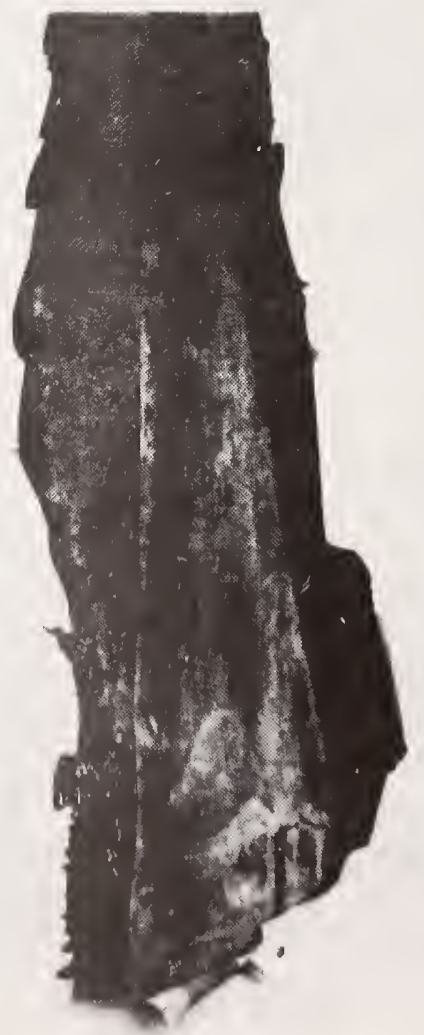

Figure 21 -- Nose Dock, MacDill AFB, Delamination of Elastomeric Coating (see Figure 20). 


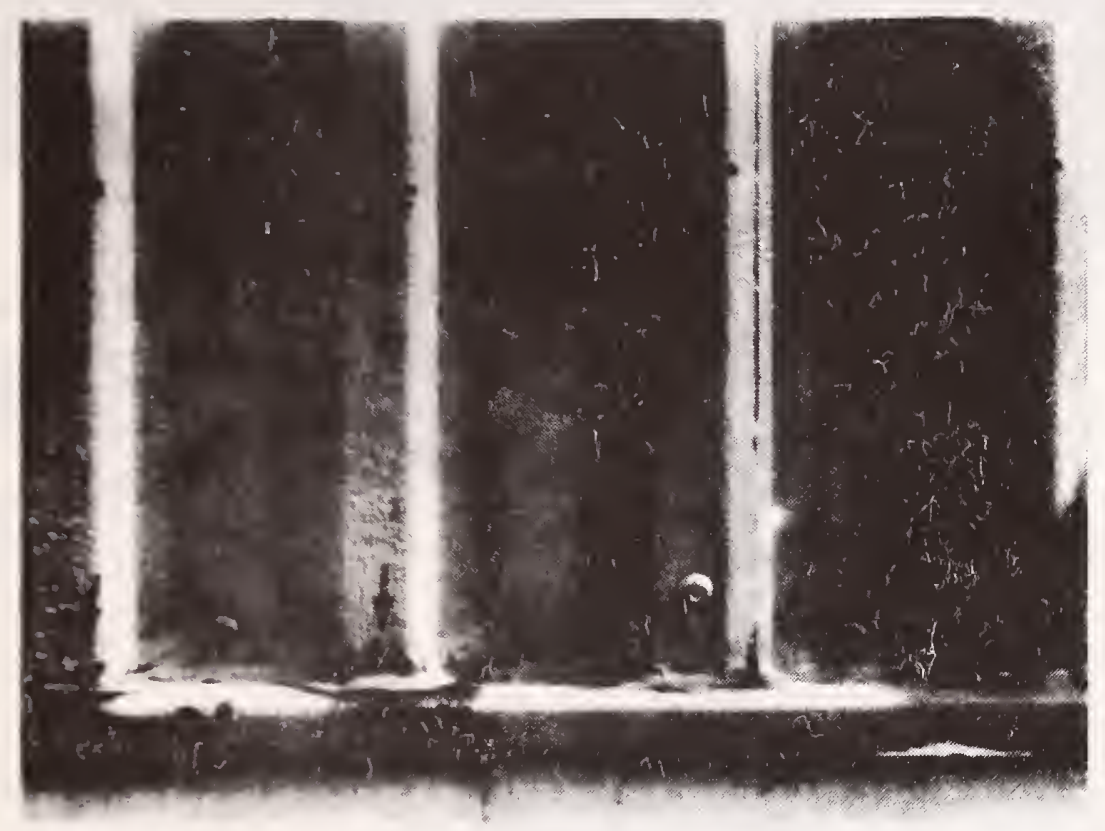

Figure 22 -- Hanger, Dover AFB, Detail at CladdingConcrete Interface (arrows show where cladding is rusting).

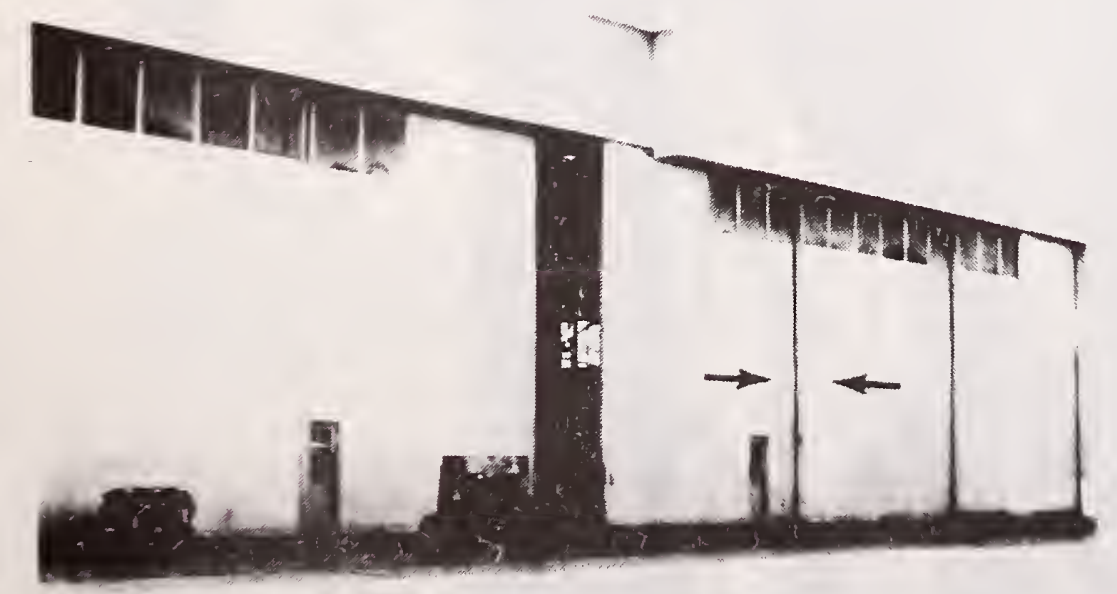

Figure 23 -- Hanger Doors, Tyndall AFB (arrows indicate area shown as close-up in Figure 24 ). 


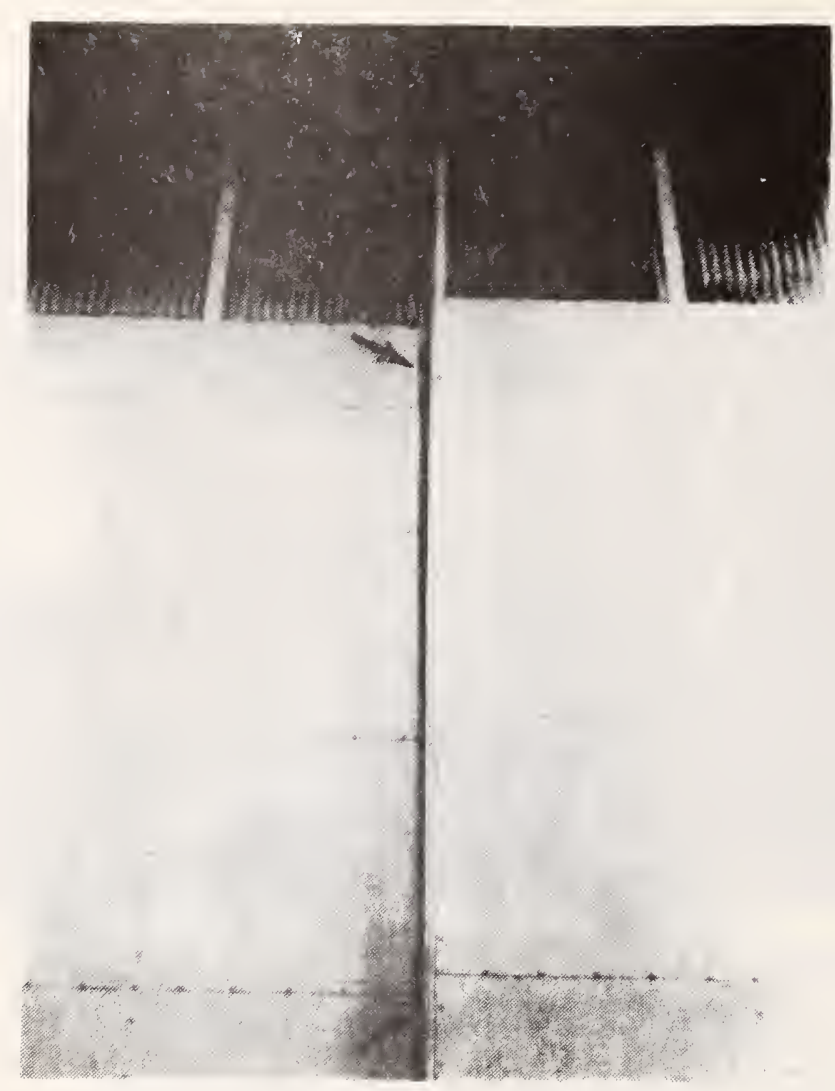

Figure 24 -- Hanger Doors, Tyndall AFB, Detail of Unpainted Area of Door Overlap (indicated by Arrows)

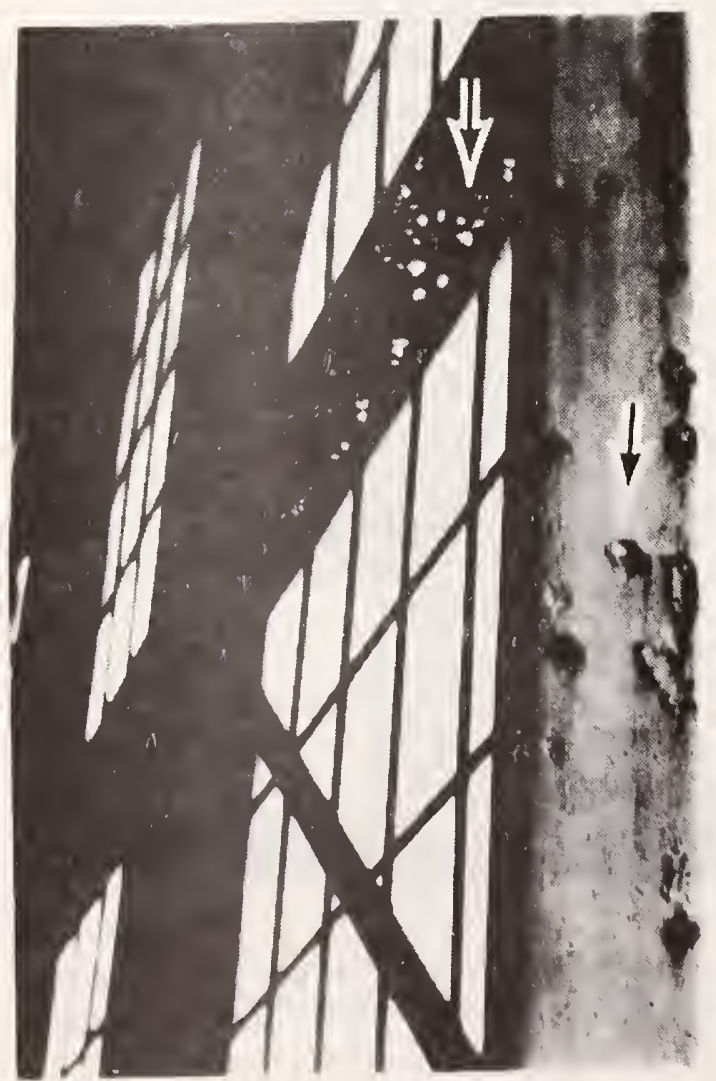

Figure 25 -- Steel Support Beams, Patrick AFB (arrows indicate areas of steel corrosion). 


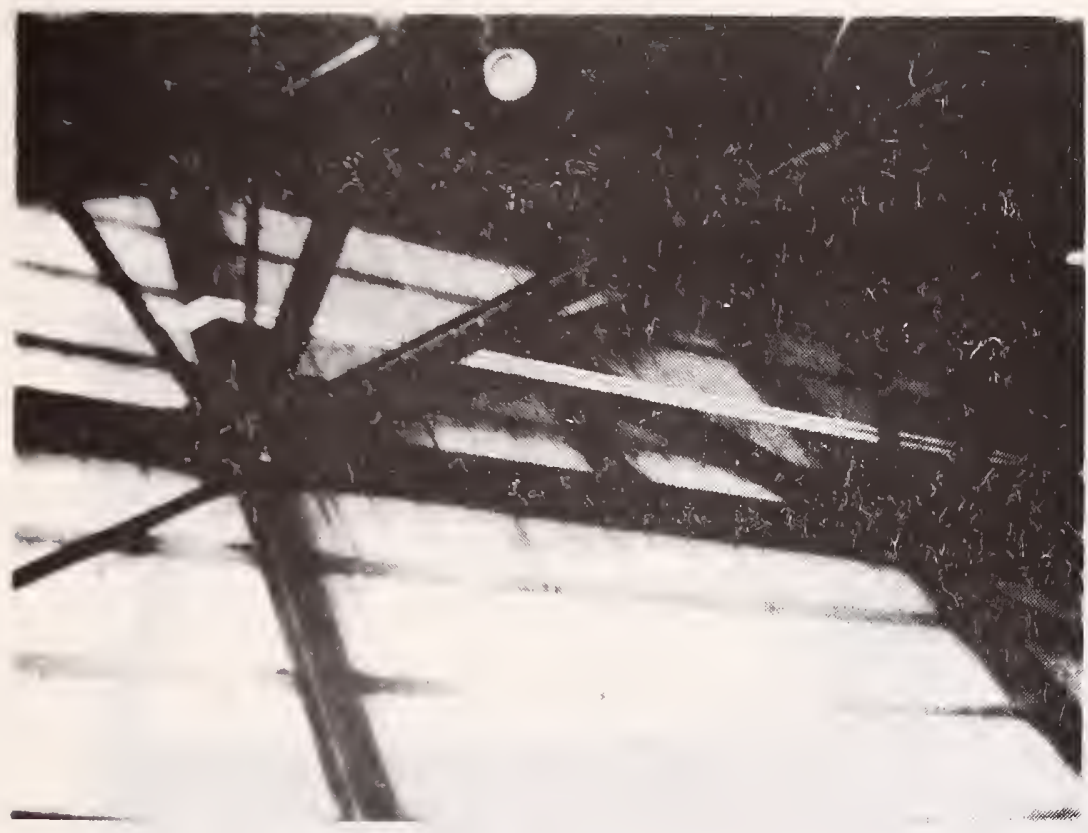

Figure 26 -- Steel Support Beams, Dover AFB.

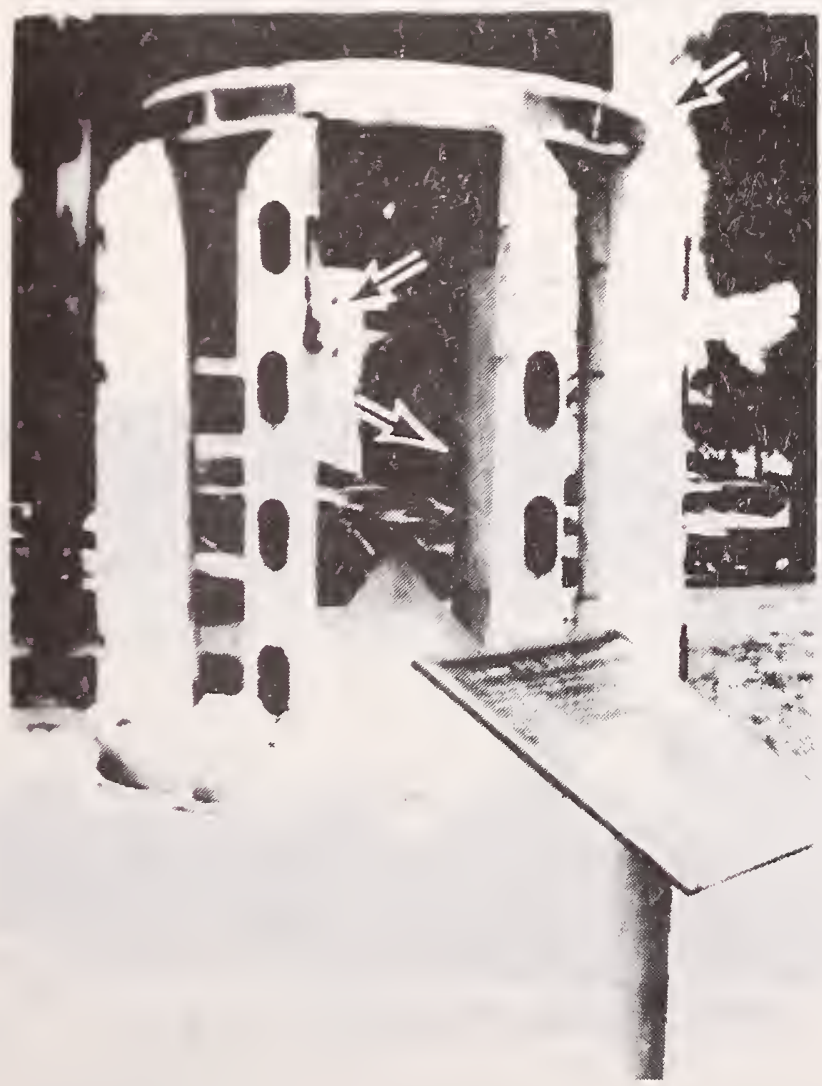

Figure 27 -- Steel Support Beams, Patrick AFB, Outdoor Exhibit of Polaris Missile (arrows indicate areas of paint failure and steel corrosion). 


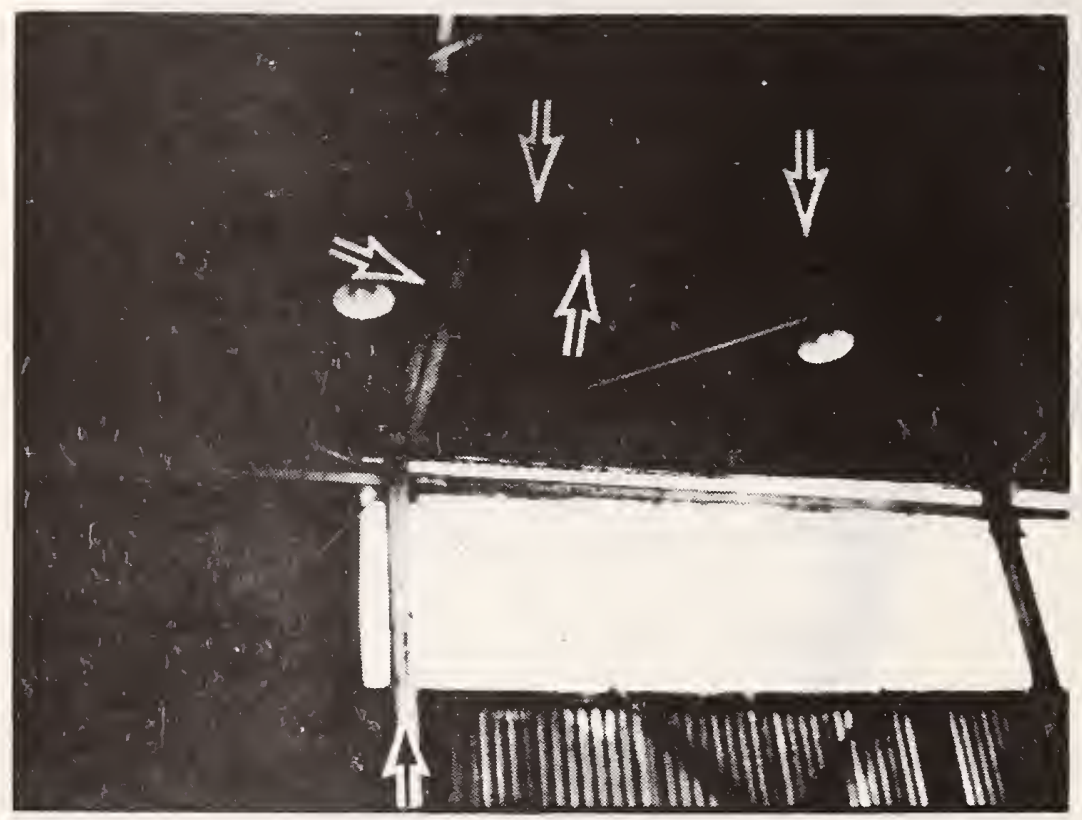

Figure 28 -- Steel Support Beam, MacDill AFB (arrows indicate corrosion of steel beams and roofing panels).

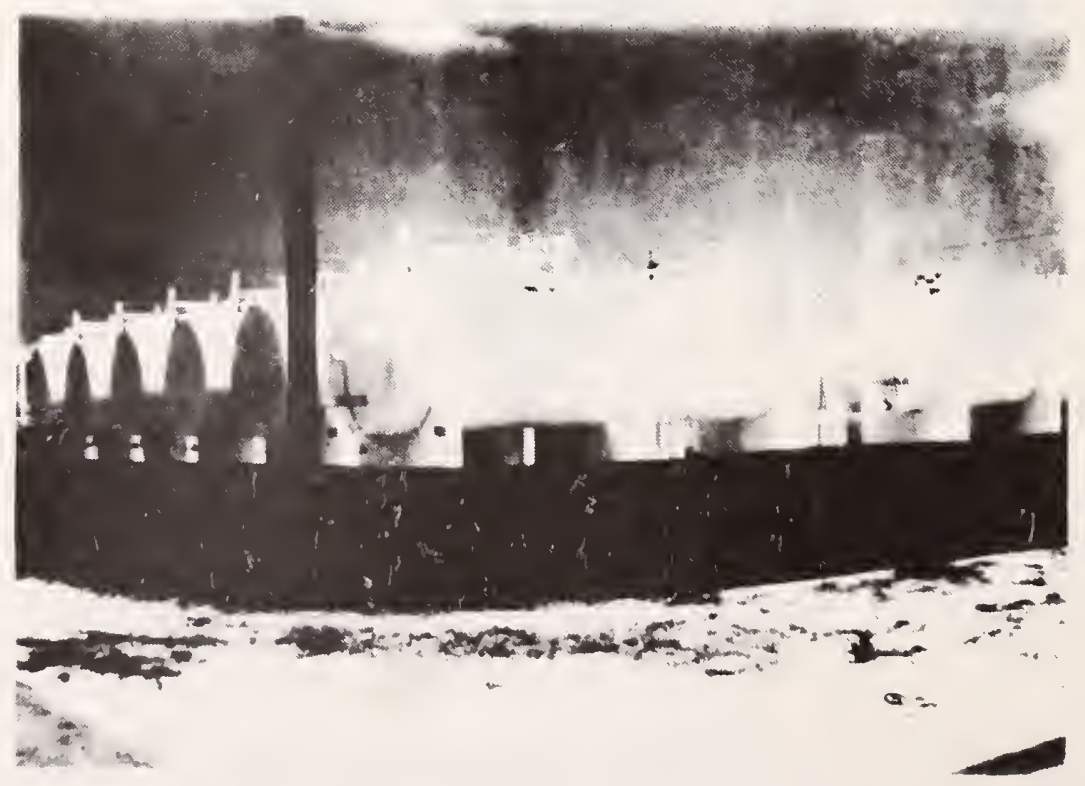

Figure 29 -- Fuel Tank Farm, Patrick AFB. 


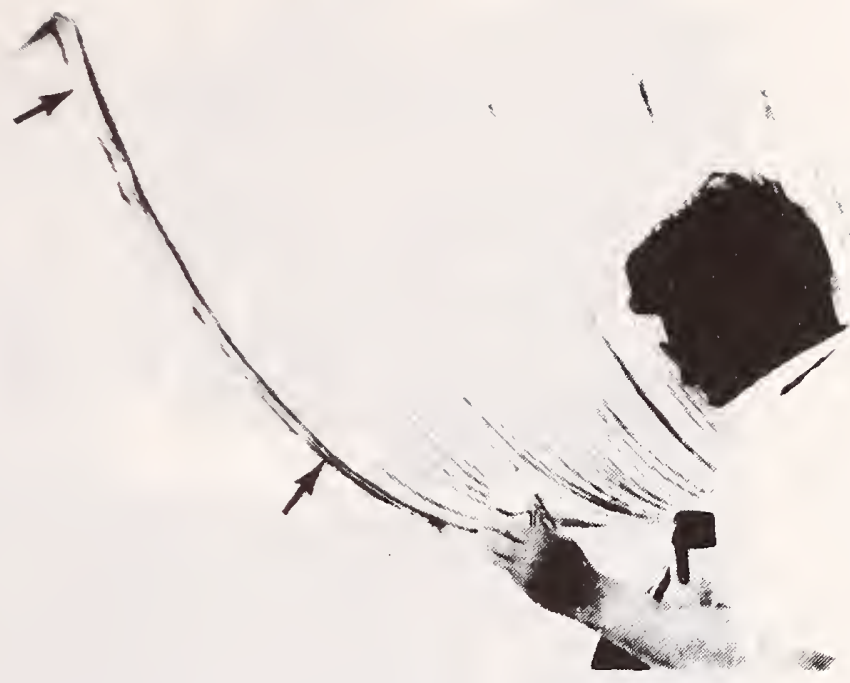

Figure 30 -- Fuel Tank Farm, Patrick AFB, Detail of Failure in Saddle Area (arrows indicate roofing felt between saddle and tank).

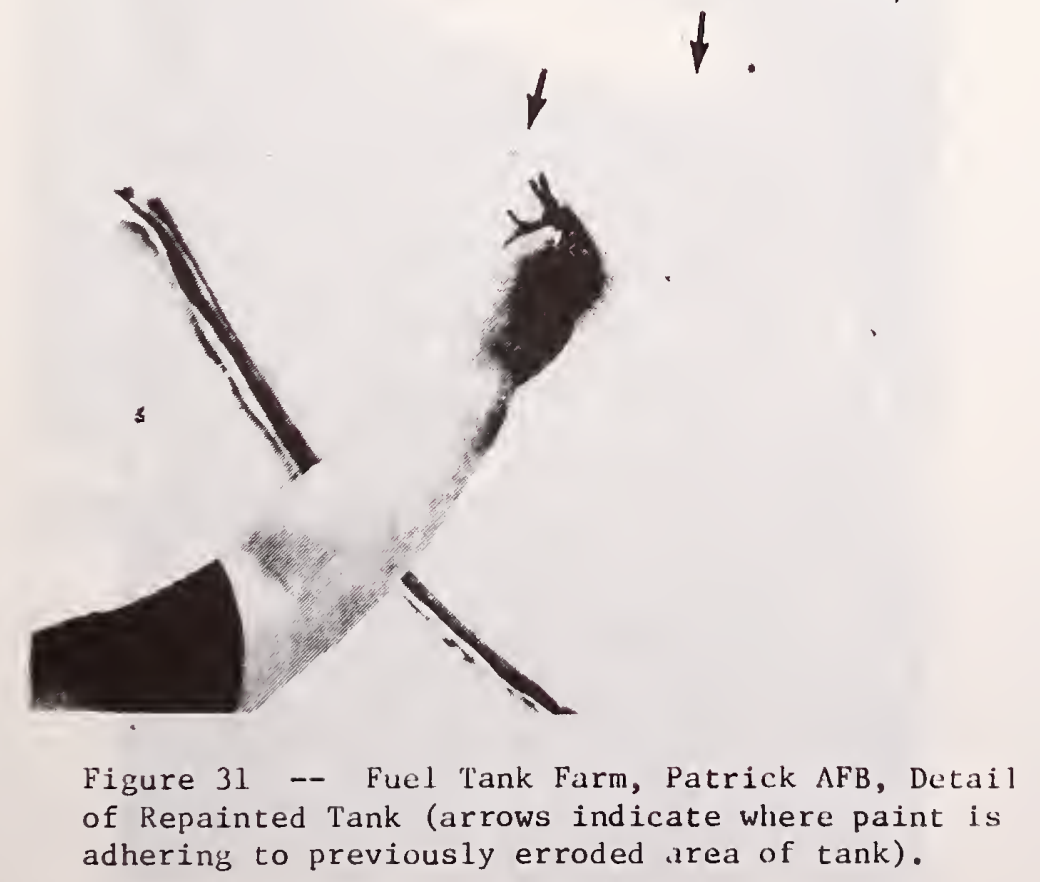




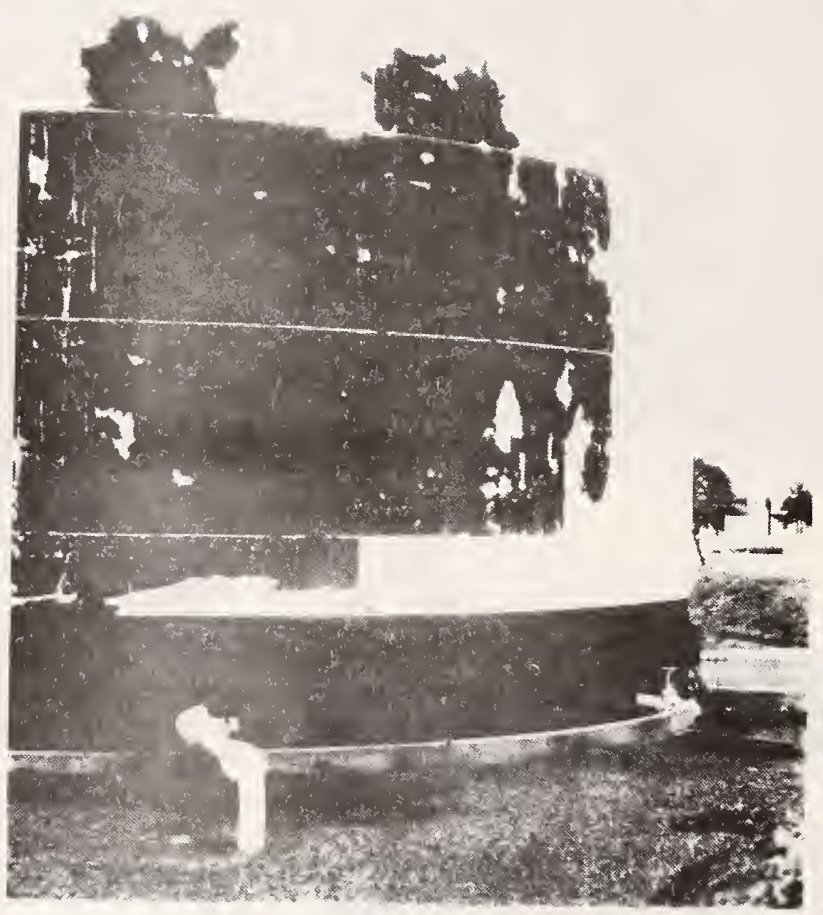

Figure 32 -- Fuel Tank, Seymour Johnson AFB.

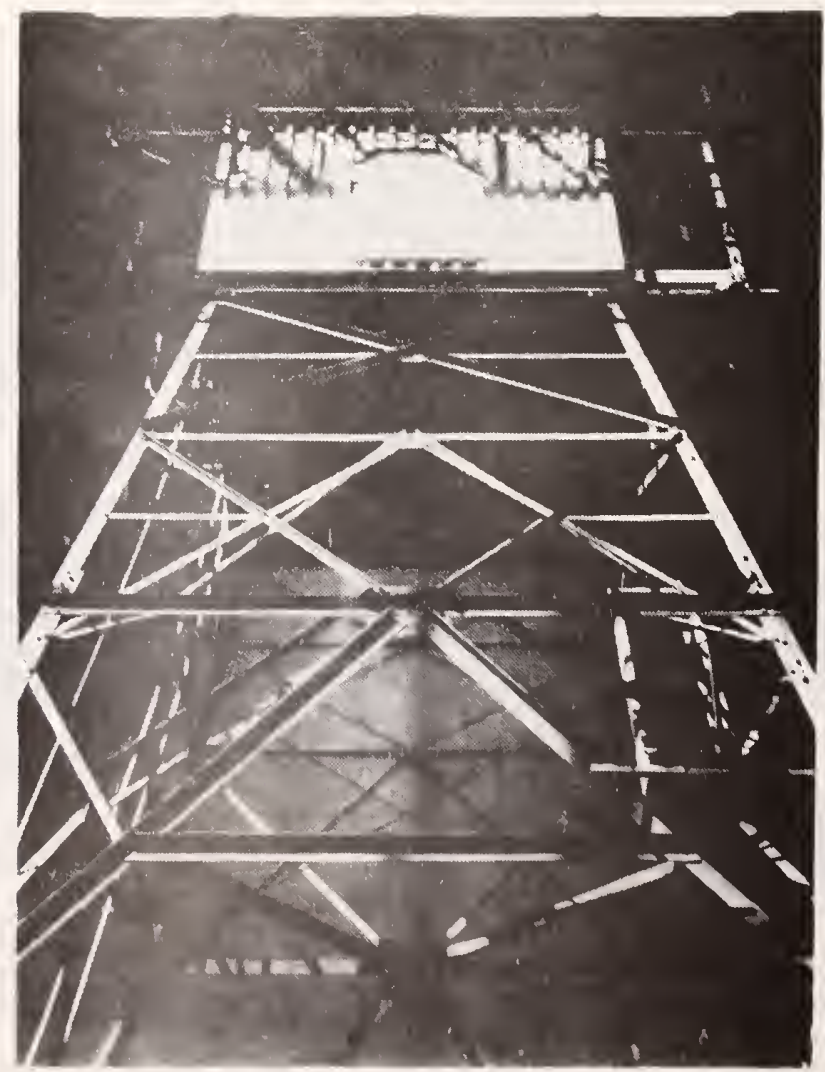

Figure 33 -- Communication Tower, Tyndall AFB. 


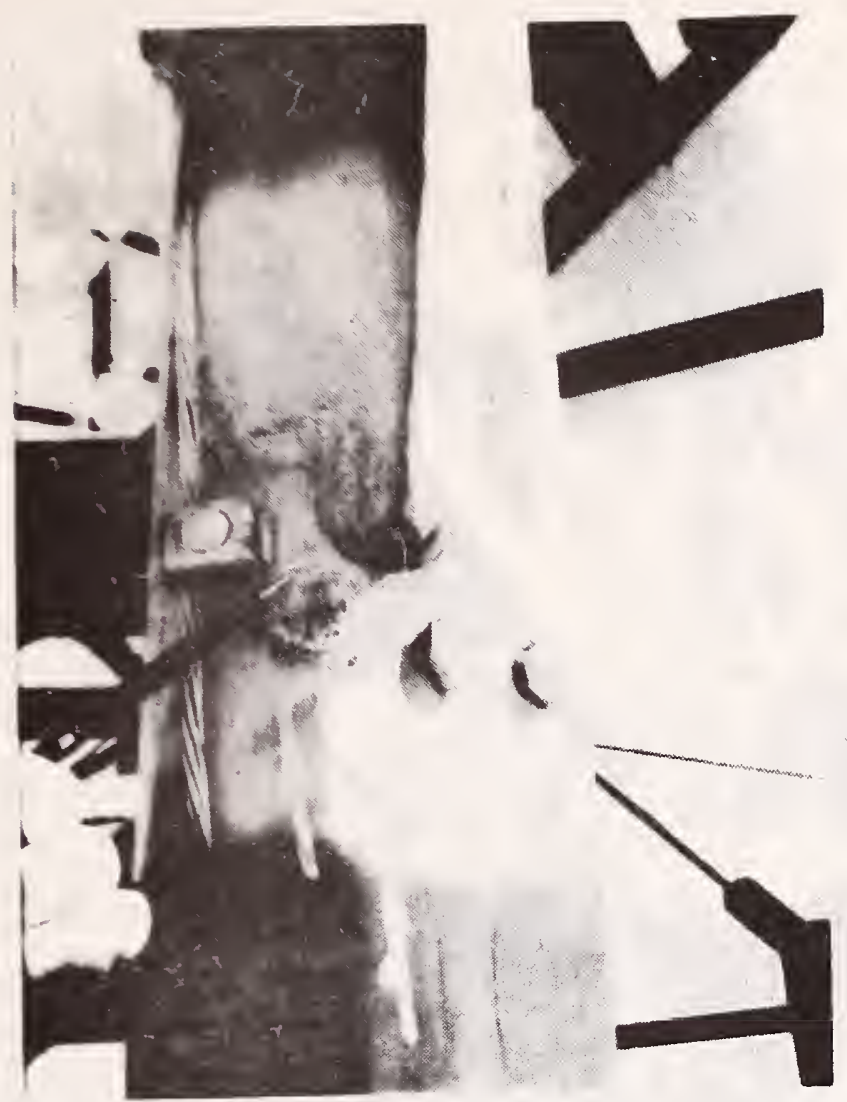

Figure 34 -- Communication Tower, Tyndall AFB.

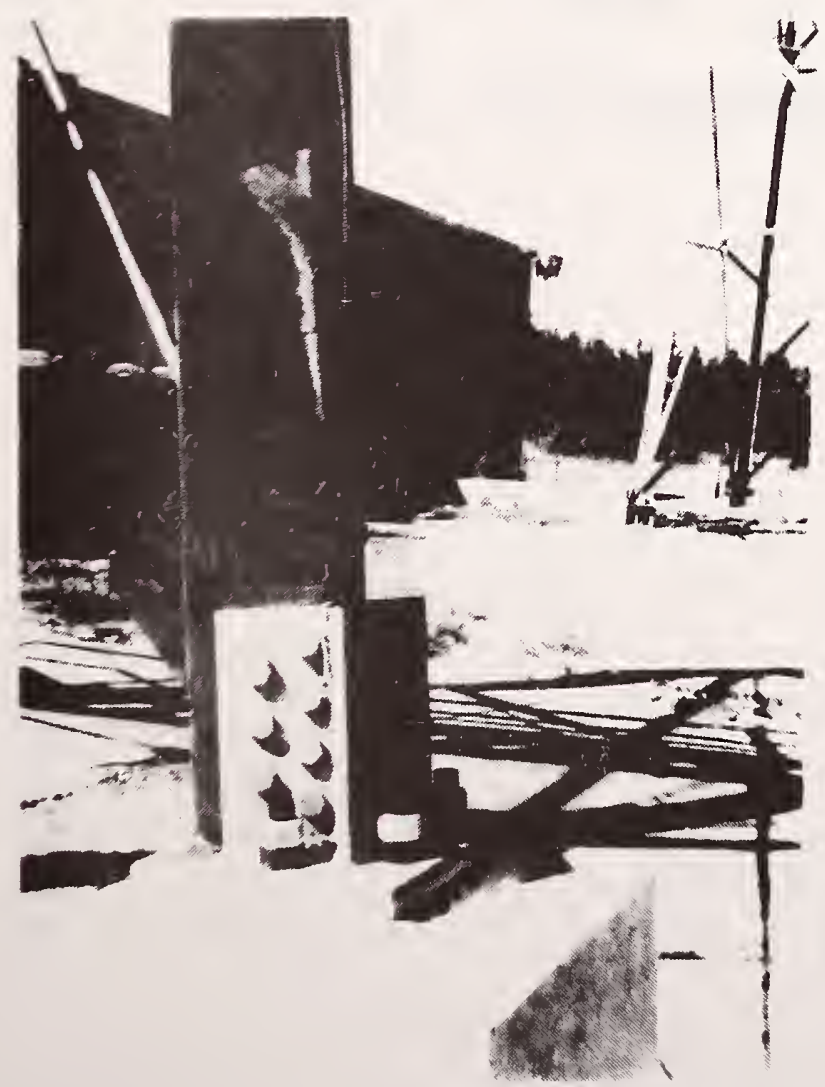

Figure 35 -- Communication Tower, Tyndall AFB. 


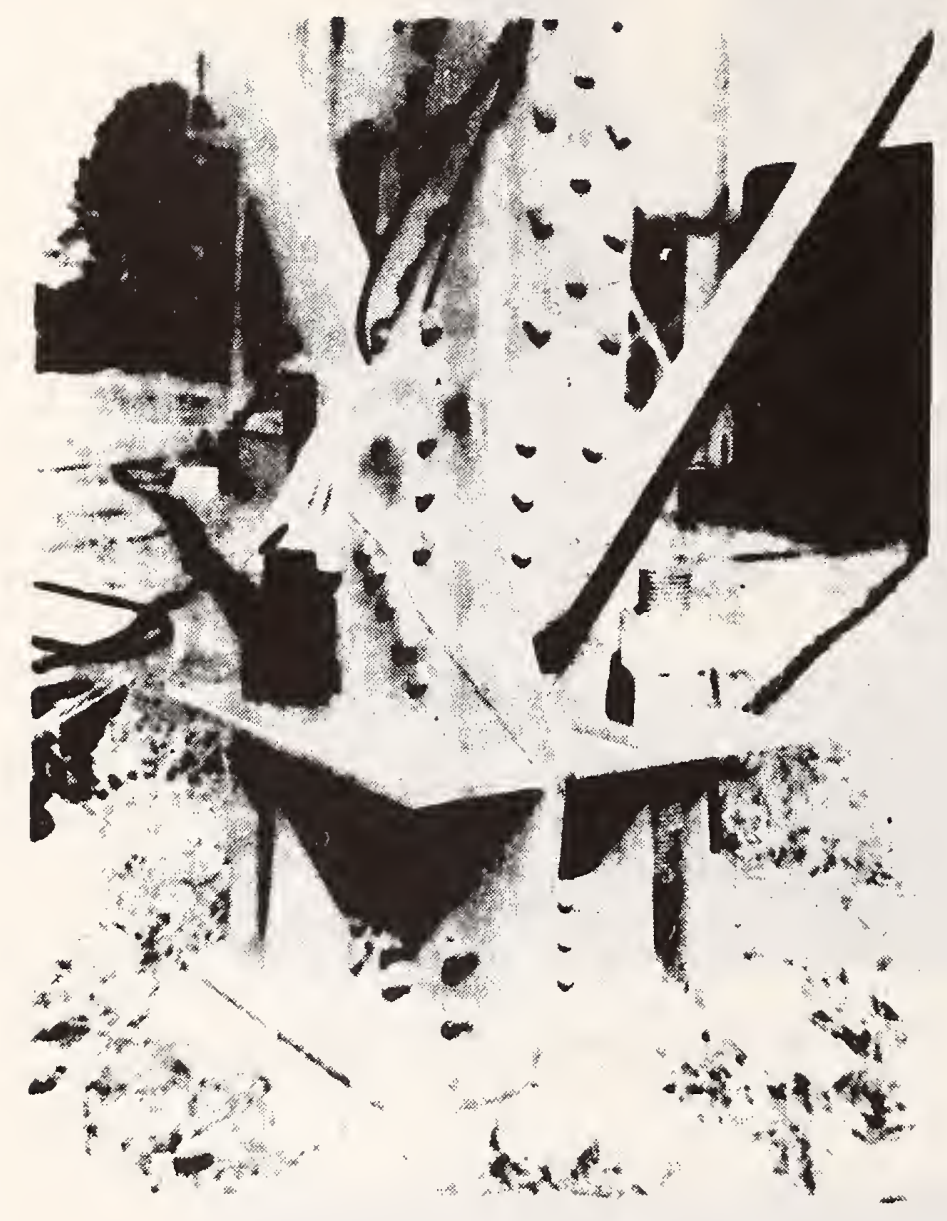

Figure 36 -- Communication Tower, Tyndall AFB. 


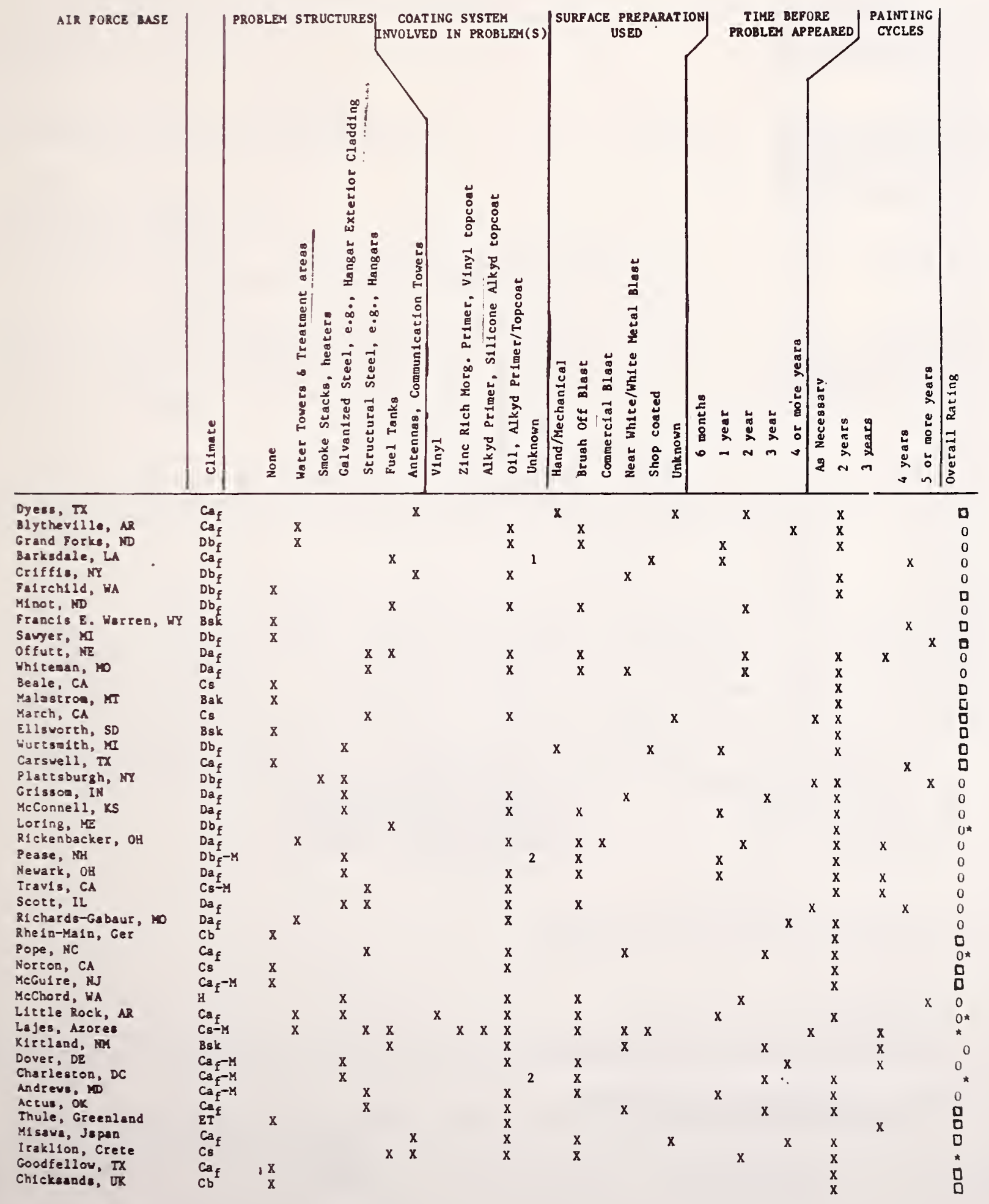


TABLE 1 -- continued。

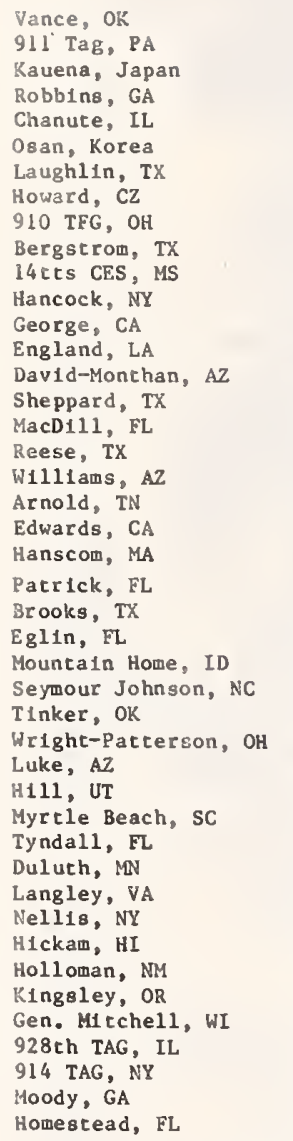

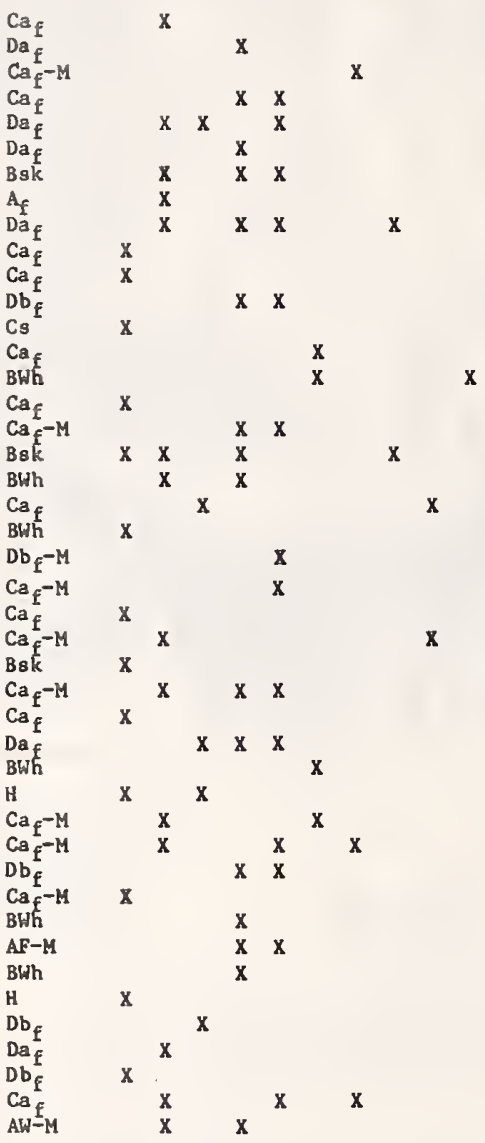

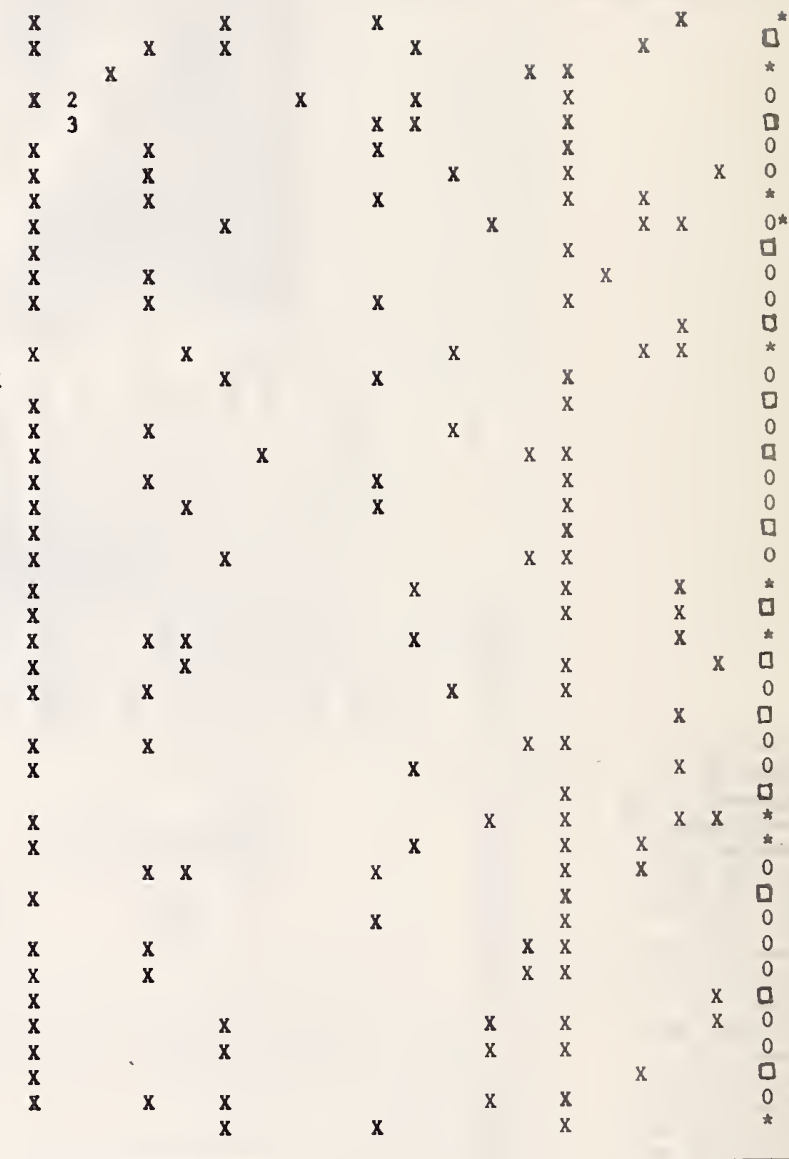

$1 \quad$ AW $=$ Tropical Savanna

BSh = Tropical and Subtropical Steppe

Bok = Middle Latitude Steppe

BWh = Tropical and Subtropical

BWk = Middle Latitude Desert

CS = Mediterranean

$-M=$ within 50 m1les of salt water

$\mathrm{Cb}=$ Marine West Coast

$\mathrm{Ca}_{f}$ - Huwld Subtropical, no dry season

Da - Humid Continental (Warm Summer)

De = Humid Continental (Warm Summer), no dry season

DF = Humid Continental (Cool Sumer)

$\mathrm{Db}_{\mathrm{f}}$ - Huw1d Continental (Cool Summer), no dry season

$\mathrm{H}=$ Highland area

2 011, Alkyd Prlmers include TT-P-57, TT-P-86, TT-P-645

011, Alkyd Topcoats include TT-E-489, TT-P-102, TT-P-10

3 Other Coating Systems:

1 Zinc Rich Inorg. primer, urethane topcoat

2 Acrylic Latex

3 Zinc Rich Inorg. primer, silicone Alkyd Topcoat

4 Star (*) Extensive coating/corrosion problems

Circle $(0)=$ Sone coating/corrosion problemg

Square $(u)=$ No coating/corrosion problems 
U.S. DEPT. OF COMM.

BIBLIOGRAPHIC DATA SHEET

4. TITLE AND SUBTITLE

Protective Coatings for Steel Structures: Part 1 - Survey of Air Force Coating Problems and Development of an Interim Guide Specification

7. AUTHOR(S)

P. G. Campbell, G. A. Sleater

9. PERFORMING ORGANIZATION NAME AND ADDRESS

NATIONAL BUREAU OF STANDARDS

DEPARTMENT OF COMMERCE

WASHINGTON, DC 20234

12. SPONSORING ORGANIZATION NAME AND COMPLETE ADDRESS (street, City, state, zIP)

Department of Air Force

Headquarters, Air Force Engineering and Services Center Tyndall AFB, FL 32403
5. Publication Date

June 1979

15. SUPPLEMENTARY NOTES

Document describes a computer program; SF-185, FIPS Software Summary, is attached.

16. ABSTRACT (A 200-word or less factual summary of most significant information. If document includes a significant bibliography or literalure survey, mention it here.)

A survey of coating/corrosion problems encountered in steel structures maintained by the Air Force was made. Eighty-eight bases responded to the questionnaire sent and the responses were analyzed for (1) the type of structure involved, (2) surface preparation, (3) coating systems used, (4) time before the problem appeared, and (5) the painting cycles commonly used by the Air Force bases. An inspection tour was made to Patrick, MacDill, Tyndall, and Elgin Air Force bases to observe coating/corrosion problems. An interim guide specification was developed for corrosion preventive coating systems on steel.

17. KEY WORDS (six to twelve entries; alphabetical order; capitalize only the first letter of the first key word unless a proper name; separated by semicolons)

Coating systems; painting cycles; steel structures; surface preparation; survey of coating/corrosion problems.

18. AVAILABILITY $\square$ Unlimited

XX For Official Distribution. Do Plot Release to NTIS

Order From Sup. of Doc., U.S. Government Printing Office, Washington, DC 20402, SD Stock No. SNO03-003-

Order From National Technical Information Service (NTIS), Springfield, VA. 22161

\begin{tabular}{|l|l|}
$\begin{array}{l}\text { 19. SECURITY CLASS } \\
\text { (THIS REPORT) }\end{array}$ & $\begin{array}{l}\text { 21. NO. OF } \\
\text { PRINTED PAGES } \\
\text { UNCLASSIFIED }\end{array}$ \\
\hline $\begin{array}{l}\text { 20. SECURITY CLASS } \\
\text { (THIS PAGE) } \\
\text { UNCLASSIFIED }\end{array}$ & 22 PrICE \\
\hline
\end{tabular}




